\title{
A model of the general circulation in the Persian Gulf and in the Strait of Hormuz: Intraseasonal to interannual variability
}

Pous Stéphane ${ }^{1,4,5, *}$, Lazure Pascal ${ }^{2}$, Carton Xavier ${ }^{3,5}$

${ }^{1}$ Sorbonne Universités (UPMC, Univ Paris 06)-CNRS-IRD-MNHN, LOCEAN Laboratory, 4 place

Jussieu, F-75005 Paris, France

${ }^{2}$ DYNECO, IFREMER, BP 70, 29280 Plouzané, France

3 LPO, IUEM, Univ. Bretagne Occ., 6 Av. Le Gorgeu, 29200 Brest, France

${ }_{5}^{4}$ Department of Oceanography, University of Cape Town, South Africa

${ }^{5}$ Ifremer, France

* Corresponding author : Xavier Carton, fax: +33 298016468 ; email address : xcarton@univ-brest.fr

\begin{abstract}
:
Previous studies modeling the circulation and thermohaline structure in the Persian Gulf have suggested that interannual variability and vertical mixing processes could explain the model biases when compared to the few observations available. Here, a realistic, interannual, high-resolution model of the Persian Gulf is presented, validated against observations and then used to describe the intraseasonal to interannual variability in the circulation, water mass formation and exchange through the Strait of Hormuz. Sensitivity experiments to model settings, in particular vertical mixing parameterizations, have been performed in order to have the best comparison with all available observations. Main circulation and water mass characteristics correspond well to observations and previous modeling studies on the seasonal timescale. A barotropic cyclonic gyre dominates the general circulation in the Gulf from April to July then breaks down into smaller features as wind intensifies and stratification decreases due to winter cooling. Dense salty water is formed in the northwest part of the Gulf and in the southern banks, but the latter reaches the Strait of Hormuz from November to April only. While temperature fluctuations are mostly seasonal, salinity has substantial fluctuations on the interannual timescale that cannot be directly related to atmospheric fluxes because of the importance of the exchanges at Hormuz for the salt budget within the Gulf. This advocates the use of atmospheric conditions including interannual variations when running models of the Persian Gulf. On the other hand, the interannual variations in the net transport at Hormuz directly follow variations in the evaporation minus precipitation over the Gulf. Thermohaline structure and circulation also vary on intraseasonal timescale, induced by the high-frequency tidal and atmospheric forcings. Finally, some biases remain in the simulations presented here, mostly due to the lack of observations of the evaporation rate, precipitation and river discharges.
\end{abstract}




\section{Highlights}

- Currents and thermohaline structure in the Persian Gulf are realistically modeled. The seasonal variability of circulation and water mass formation is re-produced. The interannual variability is related to surface fluxes and salty water formation. On the long term, the transport at Hormuz follows evaporation-precipitation.

Keywords: Persian Gulf, Strait of Hormuz, Numerical model, Hydrology, Currents, Interannual variability

\section{Introduction}

The Persian Gulf, hereafter called the Gulf, is a shallow, semi-enclosed sea which is bounded to the northwest by the delta of Iraki and Iranian rivers, to the south by a wide desert along the Iraq, Kuwait, Bahrain, Qatar, Saudi Arabia and United Arab Emirates coasts and to the north by the tall Zagros mountains along the Iranian coast. The average depth of the Gulf is $40 \mathrm{~m}$, the maximal depth is $120 \mathrm{~m}$ near the Strait of Hormuz (hereinafter referred as the strait) which connects the Gulf to the Gulf of Oman. The Gulf is about $1000 \mathrm{~km}$ long, and at most $350 \mathrm{~km}$ wide. Its area is about $239,000 \mathrm{~km}^{2}$ and its volume is about $8780 \mathrm{~km}^{3}$. The Gulf is influenced by tides, winds, heat and freshwater fluxes (including from rivers), which are reviewed below.

The direct effect of forces generating tides is very weak within the Gulf, but tides propagate into it from the Indian Ocean. Due to its dimensions, the Gulf has a self-oscillation period between 21.6 and $27 \mathrm{~h}$ (Defant, 1960). The semi-diurnal and diurnal waves generate resonance oscillations in this basin, and create amphidromic points of Kelvin-Taylor type. The tidal forcing is important for the instantaneous circulation, especially in the Strait of Hormuz and along the Iranian coast but generates weak residual currents (Hugues and Hunter, 1980 and Pous et al., 2012).

The Gulf is also driven by dominant northwesterly winds called Shamal. Other winds, called Kaus or Suhaili and blowing from the south, or Nashi blowing from the northeast, are more localized, more seasonal and often occur in bursts.

Horizontal temperature gradients within the Gulf are often weaker than those of salinity, in terms of corresponding density gradients. Salinity gradients can result either from river fluxes, from precipitation and evaporation or from exchanges between the Gulf and the Gulf of Oman. The Tigris, Euphrates and Karun river which form the Shatt-al-Arab have a seasonally variable discharge, but an annual mean of $1400 \mathrm{~m}^{3} / \mathrm{s}$ (18 cm/year) is now usually admitted. Less information is available on the discharge of the Iranian rivers Hendijan, Hilleh and Mand, for which estimates of $2000 \mathrm{~m}^{3} / \mathrm{s}$ have been quoted (Reynolds, 1993). The annual rainfall is very weak in this region; it is estimated at $15 \mathrm{~cm} /$ year, two times less than the total river discharge. Evaporation is strong and a value 
of $200 \mathrm{~cm} /$ year is most often quoted. With the values of evaporation, precipitation and river discharge quoted here, the Gulf has a $416 \mathrm{~km}^{3} /$ year water deficit and is an evaporation basin.

The water deficit is compensated for by the inflow of Indian Ocean Surface Water (IOSW) through the Strait of Hormuz; denser, more saline, waters exit the Gulf near the bottom (these are called Persian Gulf Water or PGW, [11], [20], [7], [14]). There is also a seasonal surface outflow of intermediate salinity on the southern side of the strait ([17]). The volume transport of the inflow and the total outflow has been estimated by [17] at $0.23 \pm 0.04 \mathrm{~Sv}$ and $0.21 \pm 0.05 \mathrm{~Sv}$.

IOSW has a temperature range of $23-26^{\circ} \mathrm{C}$ in winter, and $30-32^{\circ} \mathrm{C}$ in summer, and a salinity range of $36.5-37.2 \mathrm{psu}$ ([28], [35]). Observations show that, in a yearly average, the surface waters follow a cyclonic route. The formation of dense PGW $\left(\sigma_{t}>29.5\right)$ occurs essentially in the northern part of the Gulf in winter ([35]) and in the southwestern part of the Gulf in winter and early summer $([38])$, while in summer, more buoyant, warm and hypersaline water is formed in the southwestern part ([17]). The dense water from the northern formation site is advected towards the strait all year long, whereas the export of the salty water from the southwestern evaporation site is more sporadic in winter and creates salinity peaks; in late summer and fall, it is exported as an outflow of warm and salty seawater at intermediate depth ([40]). Nevertheless, the details of the circulation in the Gulf are more complex than a simple cyclonic gyre, because of the influence of seasonal variations of the exchange at Hormuz, of the river discharge, of wind forcing and because of topographic anomalies.

Observations ([17]) indicate that the PGW outflow shows substantial changes in temperature and salinity characteristics. Salinity is minimum in summer (39.3 psu) and maximum in winter (40.8 psu). Temperature is minimum in February $\left(21^{\circ} \mathrm{C}\right)$ and maximum in December $\left(25^{\circ} \mathrm{C}\right)$. The PGW outflow transport was measured over a year, and ranged between $0.08 \mathrm{~Sv}$ in December and $0.18 \mathrm{~Sv}$ in March ([38]), but without a clear pattern of seasonal variation ([17]). Tidal motions and internal tidal waves can lead to a density front in the Strait of Hormuz and to high-frequency variations in the outflow ([24]).

The first attempts to model numerically the circulation in the Gulf ([21], [8]) used three-dimensional models, with horizontal Cartesian coordinates, a mesh size of about $20 \mathrm{~km}$, and vertical geopotential coordinates. They had either rigid lid or free surface, and simplified thermohaline and mechanical forcings. These models reproduced essential characteristics of the circulation and also evidenced the elements which should be improved (seasonal variations of forcings, increased resolution). The operational model SWAFS by Horton et al. ([14]) assimilated real-time temperature and salinity data to reproduce the general circulation. The model developed by Blain ([6]) diagnosed the circulation induced by tide, heat fluxes, winds and density gradients for two extreme 
situations (January and July). But these models did not provide a detailed description of the seasonal variations. The circulation model by Kämpf and Sadrinasab ([19]), based on free-surface three-dimensional dynamical equations, with $7 \mathrm{~km}$ horizontal resolution and 5 vertical levels, and climatological forcing provided the first description of the seasonal variation of the Gulf.

This study was followed by that by Yao and Johns ([39], [40]); it investigated the circulation in the Gulf with the same hybrid coordinate model (HYCOM), with $5 \mathrm{~km}$ horizontal resolution and 13 vertical levels. This study evidenced that the seasonal variations of the surface salinity in the Gulf are chiefly due to the balance between the advection of IOSW and vertical salt fluxes induced by mixing, while the mechanical forcing only plays a weaker role. It also showed that high frequency atmospheric forcings provide more realistic surface temperatures.

A higher-resolution (1 $\mathrm{km}$ horizontally and 16 layers), primitive equation model was used by Thoppil and Hogan to model the Gulf and the Strait of Hormuz. A first study ([36]) reproduced salinity pulses of short duration, as observed, in the Strait of Hormuz. These pulses were related to the formation of cyclonic eddies upstream in the strait, due to the barotropic instability of the exchange flow in this region, and to fluctuations in the wind stress forcing. This study was followed by an investigation of the seasonality of the general circulation of the Gulf ([37]); it showed that a cyclonic gyre develops in spring in the eastern basin. In summer, this gyre becomes unstable and breaks into mesoscale eddies. This study attributed a large importance to the Ekman dynamics in the extension of the IOSW intrusion into the Gulf.

All these previous studies have shown different biases when comparing the main features (water mass properties and circulation) of the Gulf to the few (synoptic) observations available. Indeed, among these discrepancies, the simulated salinity of the PGW outflow was too salty ([19] and [40]) or too fresh ([36]) compared to observations. Actually, these studies suggest that interannual variability or vertical mixing processes (impacted by heat fluxes, induced by tidal forcing in the strait, and affected by model resolution) could explain most of the model biases. However, none of these studies describes the interannual variability of the circulation or thermohaline properties, nor combines all drivers of variability in the Gulf.

The objective of this study is to present a realistic, interannual model of the circulation in the Persian Gulf and at the Strait of Hormuz, to validate it against observations, and then to describe the variability of the circulation, water mass formation and exchange through the Strait of Hormuz on intraseasonal to interannual timescale. We use a primitive-equation, sigma-coordinate model forced by mechanical and thermohaline atmospheric fluxes, river discharges and tides. Model set up and sensitivity experiments run to optimize the realism of the solution are described in section 2 . The model is first run for 14 years with climatological forcing then for years 1994-2001 with interannual forcing. The seasonal variations are studied for an average year of the climatological run once the model has reached its steady state (section 3). The interannual variability is then detailed for years 1994-2001 (section 4). 
Intra-seasonal variability of the model is illustrated in section 5. Finally, the results of the model at higher resolution ( $3 \mathrm{~km}$ grid size instead of $9 \mathrm{~km}$ ) are discussed in view of the former results (section 6), before drawing conclusions (section 7).

\section{Model Setup}

2.1 The numerical model, initial and boundary conditions

The numerical model is composed of two parts: a 2D model of the north western Indian Ocean to provide the boundary conditions to a $3 \mathrm{D}$ model of the Persian Gulf and the Gulf of Oman. Both models have a horizontal resolution of $9 \mathrm{~km}$. Bathymetry is issued from ETOPO5 except over the Gulf where bathymetry provided by [32] is used.

The 2D model is a hydrostatic (shallow-water) model in spherical coordinates (MARS2D). In this model, quadratic bottom friction is applied, proportional to gravity, to the modulus of velocity times its vector, and inversely proportional to the squared Strickler number (equal here to $45 \mathrm{~m}^{1 / 3} \mathrm{~s}^{-1}$ ) and to the cubic root of ocean depth. Harmonic diffusion of horizontal momentum is also included in this model, with a diffusivity coefficient equal to $365 \mathrm{~m}^{2} \mathrm{~s}^{-1}$. This model is forced by the wind stress over the domain, and four semi-diurnal tidal components M2, S2, N2, K2 and three diurnal components K1, O1 and P1 are forced at the southern boundary of this large domain. This model is started from rest. It provides surface height and barotropic velocity to force the $3 \mathrm{D}$ model.

The 3D model has the same mesh size $(9 \mathrm{~km})$ and bathymetry as the $2 \mathrm{D}$ model, but it only encompasses the Persian Gulf and the Gulf of Oman (figure 1). It uses MARS3d code ([22]) with 30 sigma levels forced by the meteorological data from the European Center for Medium Range Forecast. Only the eastern boundary of the model is opened: the sea surface elevation is prescribed there with the 2D model, the temperature and salinity with the GDEM climatology and a null gradient condition is prescribed on the velocities. Horizontal viscosity is the same as for the $2 \mathrm{D}$ model. Vertical mixing is parameterized using the Gaspar turbulent closure scheme ([12]). Simulation starts from rest, with climatological temperature and salinity, and is initially forced by climatological 6-hourly forcings from February 1980 to February 1994, a period used to characterize seasonal variability in the Persian Gulf. This part of the simulation is referred to as CLIM. Then the model is run with interannual atmospheric forcings from March 1994 to December 2001 in order to study the interannual variability of the circulation and hydrography (hereafter simulation INTER). Heat fluxes are calculated using conventional bulk formulae and the relaxation method (toward climatological sea surface temperature) devised by [4] (see appendix). Salinity is excluded from this adjustment.

A higher resolution version of the $3 \mathrm{D}$ model, at $3 \mathrm{~km}$, has been initiated at the end of CLIM and forced by interannual atmospheric conditions, so as to 


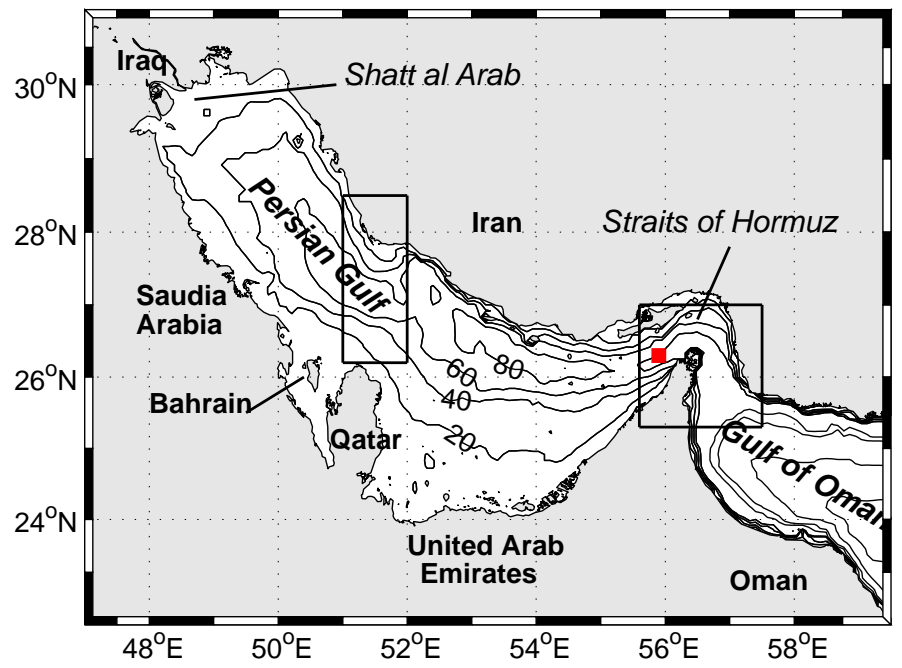

Fig. 1 Boundary of the 3D model domain; bathymetry over the Persian Gulf. The red square indicates the position of the modeled time series of temperature and salinity to compare to [17] mooring site. Black boxes show the location where temperature-salinity diagrams have been constructed for comparison with observations.

investigate the sensitivity to model resolution. All model settings other than those affected by model resolution, are the same as in CLIM and INTER. This simulation is referred to as INTER-HR and can be directly compared to INTER in order to highlight the impact of horizontal resolution.

\subsection{Sensitivity experiments}

Preliminary simulations revealed substantial biases in their mean temperature, salinity and circulation, revealing the high degree of sensitivity of the model simulation to boundary conditions and model parameters. We briefly review here the numerous sensitivity experiments that were run to optimize the model parameters and boundary forcings (minimizing the model bias).

The Gill formulation for long wave radiation was initially used ([13]). It has been shown by [17] that the net infrared flux is more accurate when using the Bignami formulation [5]. Indeed, the latter augments the heat loss and diminishes the surface temperatures, mostly in winter. Finally the annual mean long wave flux using Bignami formulation is $-82 \mathrm{~W} / \mathrm{m}^{2},-20 \mathrm{~W} / \mathrm{m}^{2}$ stronger than that obtained using [13].

Observations reported in the literature provide annual values of the evaporation rate ranging between 135 and $212 \mathrm{~cm} /$ year. Preliminary climatological simulation used an evaporation rate of $130 \mathrm{~cm} /$ year. To account for the observational uncertainties (and for the possible errors in the calculation of the evaporation rate in the model), a uniform increase of this rate by $20 \%$ was 
applied to an interannual simulation (similar to INTER), in which the evaporation rate reached $157 \mathrm{~cm} /$ year. In general over all sensitivity experiments that we performed, when the evaporation increases, the temperature decreases, the salt content and the density in the Gulf increase, so that the inflow, outflow and net transports at Hormuz also increase. For all these reasons, the simulation with evaporation rate at $157 \mathrm{~cm} /$ year yielded results that compared better with observations than initial simulation with evaporation rate at $130 \mathrm{~cm} /$ year. Hence the $20 \%$ increased evaporation rate was kept for simulations CLIM, INTER and INTER-HR that are shown below (mean fluxes for all three simulations are given in appendix). Note that we did not attempt to increase further the evaporation rate. However, it may be more appropriate to change the evaporation rate locally than uniformly. Indeed, observations ([2]) indicate stronger evaporation in coastal areas in summer.

Climatological simulation using COADS showed results comparable to CLIM but with average temperature and salinity slightly higher (due to large heat fluxes) and stronger exchanges at Hormuz.

The river freshwater forcing initially used is $1400 \mathrm{~m}^{3} / \mathrm{s}$ for the Shatt-alArab. Due to the uncertainties in river discharge, simulations were performed without river discharge and with a doubled discharge (this latter case may correspond to the addition of the Iranian rivers input). When freshwater input was increased, the exchanges at Hormuz decreased by about $0.01 \mathrm{~Sv}$, the exported PGW originated only from the Qatari coast and its salinity decreased by 0.5 . Hence modifying the river discharge can thus substantially alter salinity in the Gulf. In the end, we used the unmodified initial value of $1400 \mathrm{~m}^{3} / \mathrm{s}$ for CLIM and INTER.

Horizontal dissipation rate of the reference experiments, equal to $365 \mathrm{~m}^{2}$ $\mathrm{s}^{-1}$, is admittedly excessive. It was chosen for stability purposes near the eastern boundary of the 3D domain. However, another simulation was performed using the Smagorinsky scheme for horizontal viscosity ([34]), leading to smaller dissipation rates. The latter showed hardly any difference with the reference simulation. Therefore the reference value was kept for CLIM INTER and INTER-HR.

Two classes of turbulent closure schemes have been used: first-order schemes, including the Prandtl-Nunes scheme (depending on the mixing length and on the Richardson number [26]), the Pacanowski model ([27]) and the Munk model ([25]), and second-order schemes (k-l), including the Luyten ([23]) and Gaspar ([12]) models. Overall over the Gulf, the Prandtl-Nunes and Munk schemes produce a higher salinity than the Pacanowski, Luyten and Gaspar schemes (on the order of $0.6-0.8 \mathrm{psu}$ on average). Indeed, the latter three lead to an increase of inflow and outflow at Hormuz by changing the velocity field over the Gulf, and this may be more realistic. Pacanowski and Gaspar schemes also enhance the wind-forced circulation. At Hormuz, the Gaspar scheme reproduces the best the intensity of currents. All schemes produce the same average winter temperature, and summer temperatures are comparable except in the case of Prandtl-Nunes scheme that produces colder summer temperatures ( 0.2 to $1.5^{\circ} \mathrm{C}$ colder than obtained with other schemes). Gaspar 
scheme produces summer temperatures in the middle of the range covered by all schemes $\left(+0.5^{\circ} \mathrm{C}\right.$ warmer than Prandtl-Nunes).

\subsection{Model outputs}

Diagnostics presented below either use monthly averages of the model outputs, either higher frequency outputs. The latter are extracted every 7 days, after applying a low-pass filter over 71 hours (Demerliac filter, [10]) to remove the effect of barotropic tides. Hence they can be considered as high frequency (daily) snapshots of the model, free of the signature of tides. Temperature and salinity averaged over the Gulf are, additionally, low-pass filtered with a 10-day cut-off period.

\section{Mean circulation, thermohaline structure and seasonal variability in the Gulf and the strait}

We first diagnose simulation CLIM to illustrate the mean circulation, thermohaline structure and seasonal variability in the Gulf.

Adjustement from initial state takes less than 1 year for temperature and about 5 years for salinity (figure 2, the period 1994-2001 will be discussed in section 4). This adjustment time for salinity, comparable to that obtained in other studies ([19], [36] and [39]), depends on many processes: freshwater advection from the Gulf of Oman, production of denser water in the Gulf and its exit through the Strait of Hormuz, convection in areas where salinity increases noticeably, circulation in the Gulf. Note that this spin-up time is longer than the residence time of water masses in the Gulf, which was estimated at 2-5 year by different authors. Transports across the Strait of Hormuz reach their steady values within 1-3 year, and reach, on average, - $0.202 \mathrm{~Sv}$ for the inflow, 0.194 Sv for the outflow and $-0.0085 \mathrm{~Sv}$ for the net flux. The latter reflects a net inflow of water which, added to the river discharge, corresponds to an evaporation rate of $1.58 \mathrm{~m} /$ year over the whole surface of the Gulf (see appendix). Note that the mean value of the model outflow is consistent with the annual average of $0.21 \mathrm{~Sv}$ observed by [17].

\subsection{Circulation in the Gulf}

Between April and July, the barotropic circulation is mainly composed of a cyclonic gyre in the southeastern basin (east of $51^{\circ} \mathrm{E}$ ); this gyre grows eastward in April and it is accompanied between June and August by an anticyclonic gyre in the northwestern basin (not shown). From July to October, the main cyclonic gyre gives way to several smaller eddies (diameter of $120 \mathrm{~km}$ ) as found in [37]. In December, as wind intensifies and stratification decreases due to winter cooling, those structures are replaced by much smaller structures and the currents seem to be directly influenced by wind patterns and near 

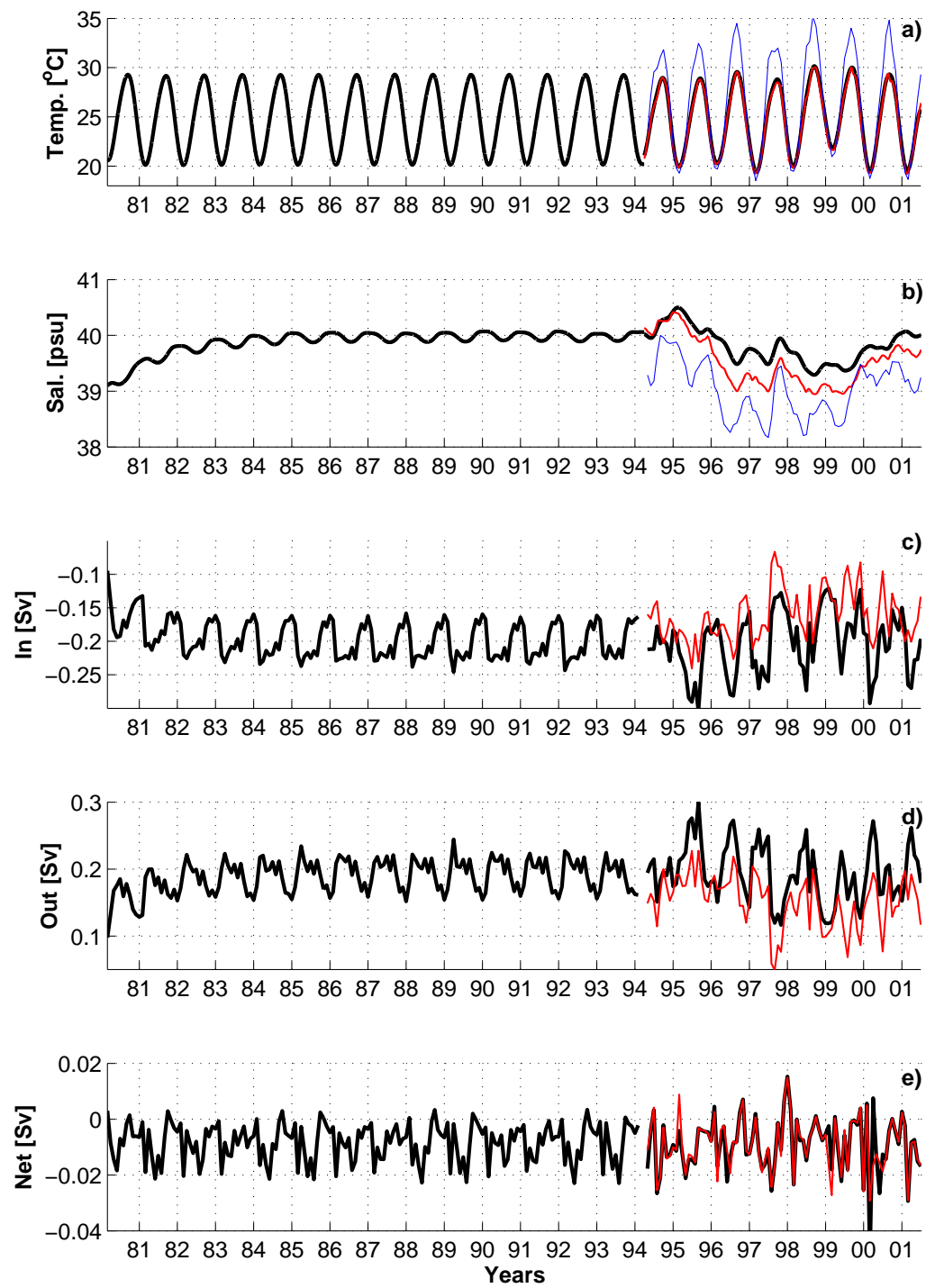

Fig. 2 Time evolution of (a) temperature averaged over the Gulf for years 1981-1994 (CLIM, black line) and 1994-2001 (INTER, black line and INTER-HR, red line); (b) salinity averaged over the Gulf (same color coding as for temperature); (c) inflow, (d) outflow and (e) net transports across the Strait of Hormuz (monthly data, in Sv, CLIM and INTER in black, INTER-HR in red). Upper panels also show the monthly SST (a, blue line) and SSS (b, blue line) from INTER for years 1994-2001. 
the Strait of Hormuz, an inflow heads southwestward along the Emirati coast and forms a front with the outflow currents. The average magnitude of the barotropic currents here is stronger in summer $(10-20 \mathrm{~cm} / \mathrm{s})$ than during winter $(5-10 \mathrm{~cm} / \mathrm{s})$ and is comparable with the values found by [6] or [37].

Surface circulation is first described in summer, when coherent features are mostly visible (figure $3 \mathrm{~b}$ ). In the Northwestern part of the Gulf, where the circulation is dominated by the influence of wind and of river discharge ([33], [31]), the currents head southeastward along the Iranian and Arab coasts, producing an upwelling along the former and a downwelling along the latter. The monthly averaged surface currents reach up to $10-20 \mathrm{~cm} / \mathrm{s}$ in magnitude. In the eastern part of the Gulf, the IOSW inflow plays an important role in shaping the surface circulation, in addition to the influence of the wind. The main branch of IOSW flows along the Iranian coast in spring and summer (up to $51^{\circ} \mathrm{E}$ ), a current hereafter referred to as the Iranian Coastal Current (ICC). Velocities of $20-30 \mathrm{~cm} / \mathrm{s}$ are found on average in summer there, in agreement with measurements by [16]. At $50^{\circ} \mathrm{E}$, the two coastal currents of the western basin join and form a southeastward flow with the IOSW current that recirculates cyclonically. In both seasons, another branch of inflowing IOSW follows the Emirati coast and joins the main branch along the Iranian coast further west.

In winter, the mean circulation is overall weaker because mesoscale activity is much stronger (figure 3a). Hence the circulation features described the rest of the year are much weaker or hardly visible. Still, there is a predominant cyclonic circulation in the eastern basin (note that it is much smaller than the cyclonic circulation observed in summer). As mentioned above, the strong mesoscale activity in winter is primarily due to the increase in wind forcing and the decrease in stratification due to winter cooling.

The bottom circulation in the Gulf is less well known (except via the work by [39]). In the western basin, the northernmost currents head towards the Shatt-al-Arab and recirculate there in small gyres. South of $29^{\circ} \mathrm{N}$, the main current is southeastward and follows the central axis of the Gulf; it feeds the outflow through the Strait of Hormuz (figure 3c). In winter, mesoscale gyres are superimposed on this circulation, and branches of circulation leave the Arab coast to join the central current. The monthly averaged currents do not exceed $10 \mathrm{~cm} / \mathrm{s}$. In the eastern basin, two important features are noticed:

- the southeastward flow coming from the western basin continues to the strait; this branch is visible at all seasons;

- from November to May, several branches of current leave the southern coast and join the main stream in the central part of the Gulf; their velocity is typically $10 \mathrm{~cm} / \mathrm{s}$; they carry salty waters from the shallows near Qatar. This feature is in agreement with current meter measurements in this region in spring $1992([1])$.

In late summer, as found in [37], ICC becomes unstable and this generates barotropic mesoscale features (known as Iranian Coastal Eddies) characterized by cold and salty cores relative to the surrounding water masses (figure 4). Those features contribute to exporting fresh IOSW offshore at their perimeter, 


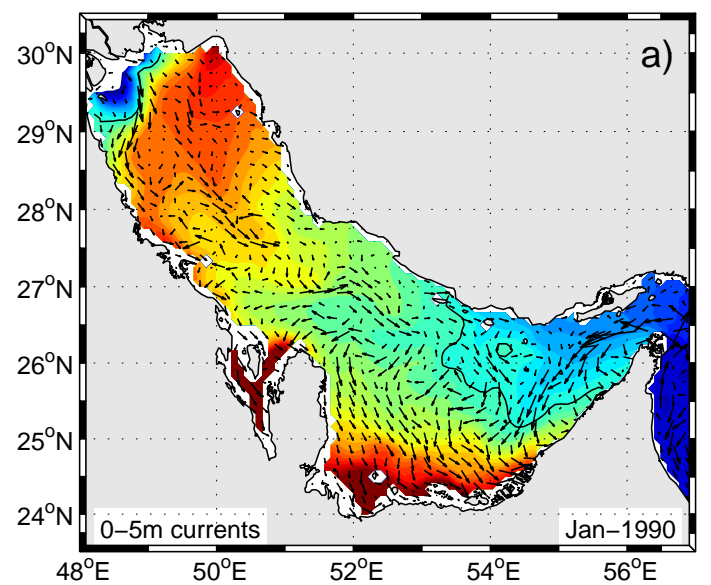

$20 \mathrm{~cm}_{\mathrm{s}} \mathrm{s}^{-1}$
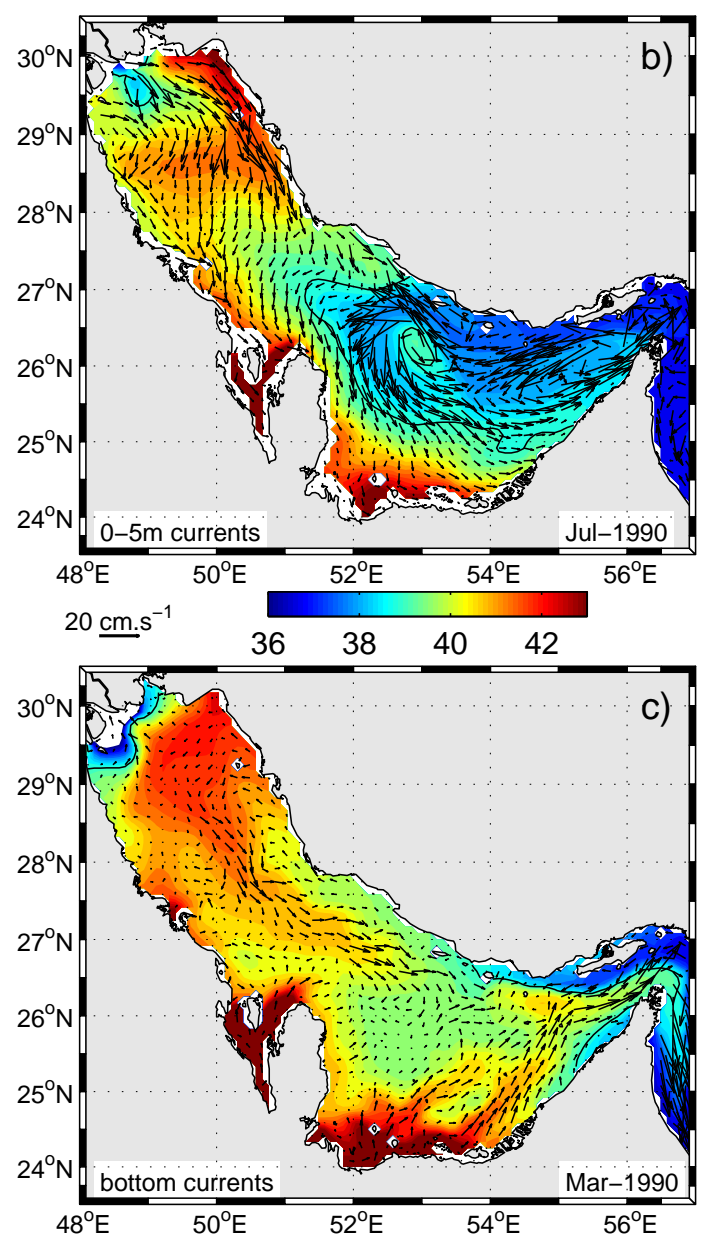

$10 \underline{\mathrm{cm}} . \mathrm{s}^{-1}$

Fig. 3 Monthly averaged salinity and velocity (only one arrow every $20 \mathrm{~km}$ is shown) at the surface in January (a), July (b) and at the bottom in March (c). Isohaline 39.0 is located by the black line. 

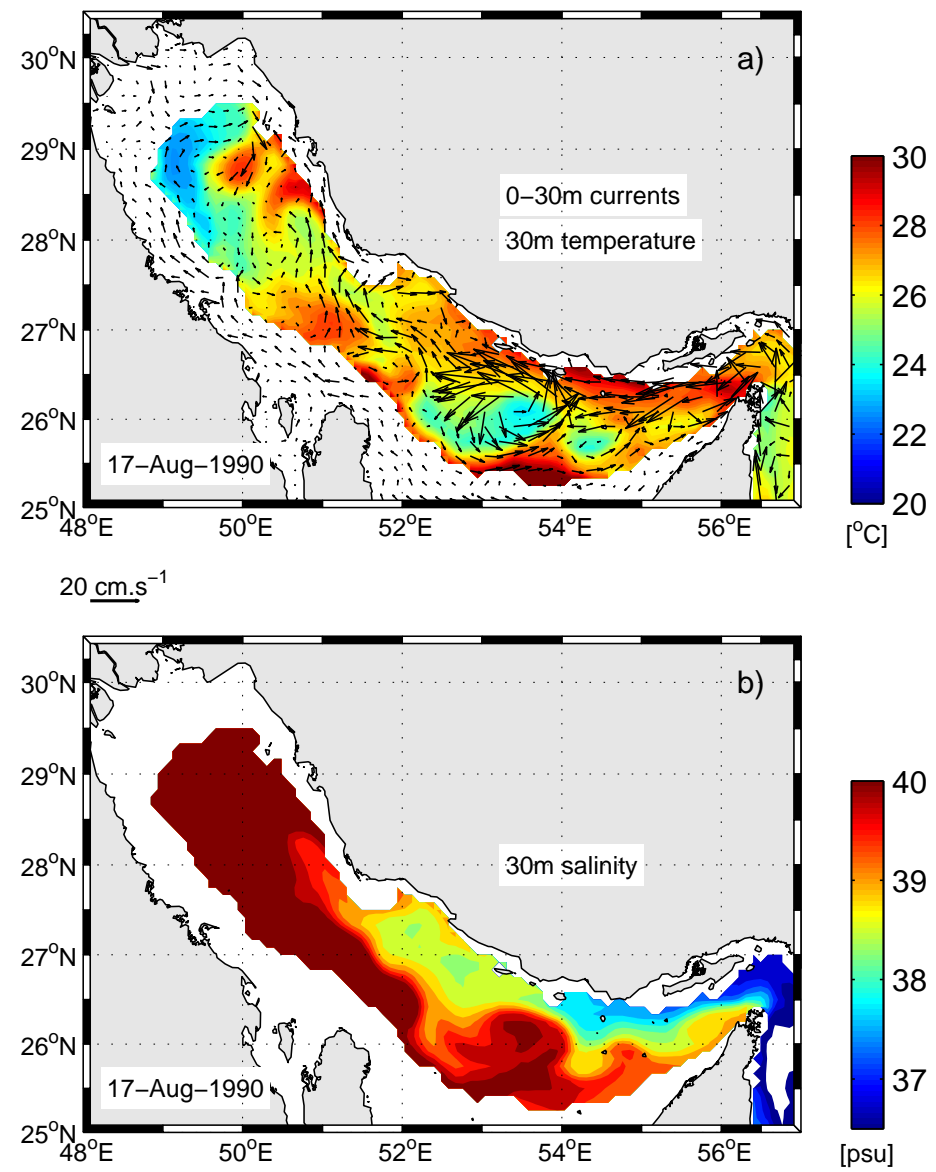

Fig. 4 Snapshot of temperature and velocity (only one arrow every $20 \mathrm{~km}$ is shown) in (a) and salinity (b) in August 1990. Currents are averaged over the upper $30 \mathrm{~m}$, while temperature and salinity are extracted at $30 \mathrm{~m}$ depth.

as can be seen from the tongues of freshwater found in between the salty cores. In the present model, they seem to be less stationary than described in [37], but this may depend on model resolution, as described below (section 6.1).

\subsection{Thermohaline structures in the Gulf}

The surface salinity maps (figure 3, color shading) show that a fresh plume heads from the Shatt al Arab towards the Saudi coast in winter (panel a) and towards the Iranian coast in summer (panel b). The fresh IOSW inflow extends from the Strait of Hormuz up to $27^{\circ} \mathrm{N}$ along the Iranian coast in summer, when the inflowing transport at the strait is maximum and there is a cyclonic recirculation in the Gulf; in winter, IOSW remains confined near Hormuz. 
This is in agreement with the MOODS database ([35]). In both seasons, high salinity waters (with $S>43$ ) are located near the southern coast.

The saltiest hence densest water masses $\left(\sigma_{t}>29.5\right.$, referred to as PGW) of the Gulf are formed in winter in the northwest and in the southern banks. They all reach Hormuz but in a partitioning that depends on the season: in summer, PGW at Hormuz comes from the northwestern part of the Gulf, along the central trough of the basin; from November to April, they come from the southern banks (see figure 3c, showing bottom salinity in March when both branches can be seen). The latter is interrupted in late spring and summer because the warming of the southeastern part of the Gulf creates a bulk of relatively light water masses, $50 \mathrm{~km}$ offshore the Emirati coast, that confines the dense salty water masses to the coast. Note that near the strait, PGW salinity decreases by vertical mixing due to the interaction between tide and topographic irregularities (this decrease can also be seen in the MOODS database).

Maps of surface temperature are not shown for concision, but the model reproduces the northwest-southeast gradient of surface temperature as observed ([7], [33]): the southeastern part of the Gulf is warmer than the northwestern part (not shown). The model also reproduces well the seasonal variations of surface temperature, the minima, near the Shatt al Arab in February, and maxima, in August and September along the Emirati coast, where the model surface temperature reaches up to $35.5^{\circ} \mathrm{C}$, about $1^{\circ} \mathrm{C}$ warmer than observed ([28]). The bottom temperatures display a similar gradient to that at the surface in winter (not shown). In summer, the gradient is nearly perpendicular to isobaths, which is consistent with the maps from the MODAS database ([6]).

Seasonal variability of the thermohaline characteristics is illustrated in the central part of the Gulf (figure 5) and compares well with observations ([3] in figure 6 of [19]). Stratification is very weak in winter (panel a), when temperature is nearly homogenous as observed. Upper ocean warms up in spring (panel b), mostly due to radiative heating rather than to the inflow of warm waters (not shown) which is consistent with observations ([35]). In winter and spring, the model appears slightly saltier than observations of [3] but this may reflect interannual variability partially included in synoptic observations (see below section 4.2). Stratification is maximum in summer (panel c), when temperature ranges from $19^{\circ} \mathrm{C}$ to $33^{\circ} \mathrm{C}$, and is visible in temperature, salinity as well as density, with fresh and warm modified IOSW in the upper ocean and saltier and colder dense water masses at depth. Note that the densest water masses, throughout the year, are the saltiest, as observed.

\subsection{Exchanges in the Strait of Hormuz}

Circulation at the Strait of Hormuz consists of a branch heading toward the Gulf, in the northern part of the strait (hereafter the inflow) and a branch heading out of the Gulf, in the southern part (hereafter the outflow). While the inflow branch has maximum velocities in the upper ocean, the outflow 

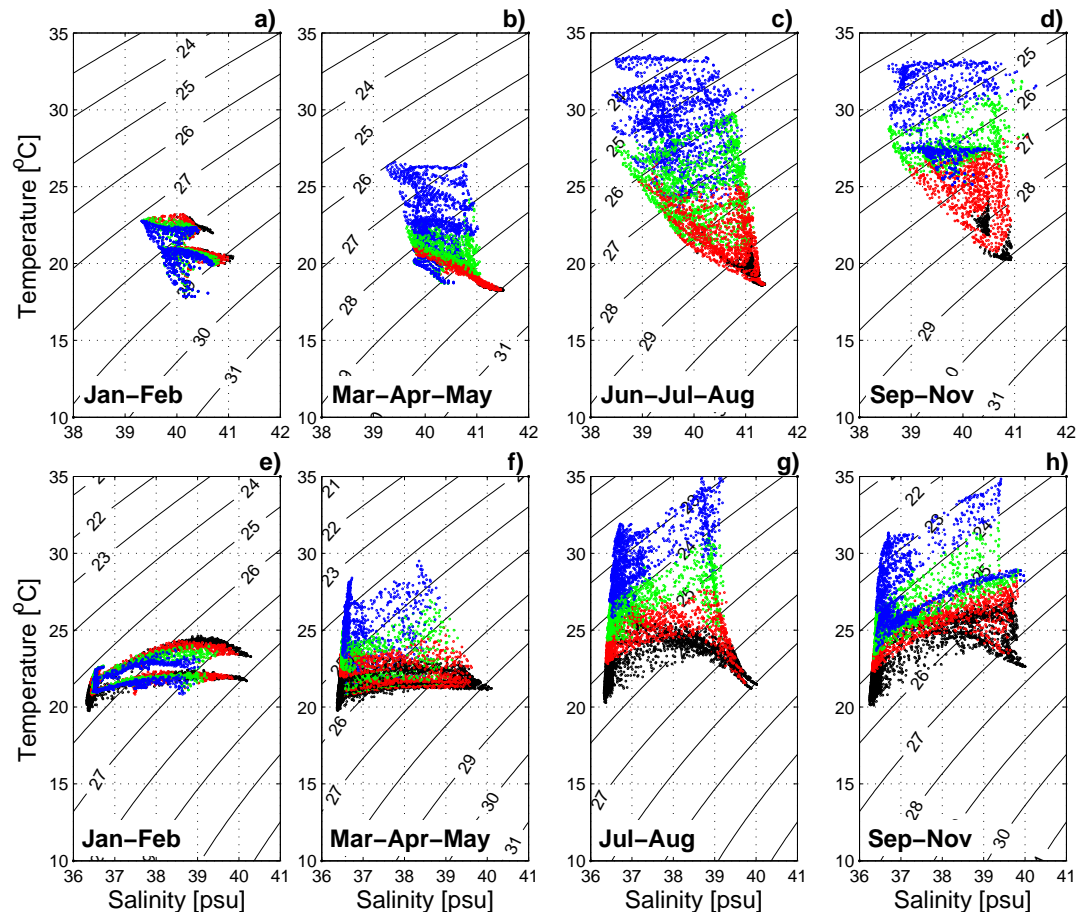

Fig. 5 Seasonal Temperature-Salinity diagram in the central region of the Gulf (top, see boxes in figure 1) and in the Strait of Hormuz (bottom), at selected depth intervals (5-20m in blue; $25-35 \mathrm{~m}$ in green; $40-55 \mathrm{~m}$ in red and $60-100 \mathrm{~m}$ in black), based on monthly temperature and salinity.

branch has its core in the deep ocean, but both branches reach the bottom and the surface (mean circulation is not shown but those features can be see in monthly average of August 1999 shown in figure 8, a, c and e that is described below). The inflow occupies about two-thirds of the section (see also [17]). The structure of both branches, in particular the $0 \mathrm{~cm} / \mathrm{s}$ isotach that separates the two branches, does not vary much with season. However, the currents of both branches are minimum in winter and maximum in spring-summer (monthly averages reach up to $\pm 20 \mathrm{~cm} / \mathrm{s}$ while snapshots reach up to $-30 \mathrm{~cm} / \mathrm{s}$ in the outflow and up to $45 \mathrm{~cm} / \mathrm{s}$ in the inflow). Similarly, the inflow and outflow transports are minimum in winter $(0.16 \mathrm{~Sv}$ for inflow, $0.15 \mathrm{~Sv}$ for outflow $)$ and maximum in spring-summer $(0.23 \mathrm{~Sv}$ for inflow, $0.22 \mathrm{~Sv}$ for outflow, see figure 2 , c and d), in agreement with observations (recalled in the introduction).

Characteristics of water masses at the strait are very close to observations throughout all seasons (figure 5, to be compared with observations from [3] shown in figure 4 of [19]), in particular those of IOSW, which salinity ranges from 36.5 to $37.0 \mathrm{psu}$ as observed, and PGW, which salinity is about $39.5-40.3$ psu. Note that bottom salinities that characterize PGW have little seasonal variability but are saltiest between August and February. The highest 
simulated salinity is $40.3 \mathrm{psu}$ close to the highest value (40.6 psu) observed in 1997-1998 by [17]. Note that the previous modelling studies have shown an important variability for this highest salinity value (39.6 in [36], up to 41 in [19] in and more than 41 in [40]). Seasonal temperatures at the strait, from $22^{\circ} \mathrm{C}$ at the bottom to $33^{\circ} \mathrm{C}$ at the surface in July-August, and within $22-23^{\circ} \mathrm{C}$ in March, are consistent with observations by [17] in July 1997 and March 1997 and 1998.

At the strait, isopycnals are not aligned to isotachs, which suggests that an important part of the circulation is not geostrophic (not shown). As noted in the central part of the Gulf, stratification is weaker in winter and stronger in summer. Maximal densities lie below $75 \mathrm{~m}$ depth, in a homogeneous layer, near the coast of Oman, in March. The isopycnal surface above this layer tilts upward to the south, in agreement with an outflow current of water masses lighter than PGW in the upper ocean. Hence the circulation at Hormuz is close to a three-structure flow as mentioned by [17]: an inflow of IOSW, near the surface, in the northern part of the strait, and outflow of intermediate water (a priori due to the mixing of IOSW and PGW) near the surface in the southern part of the strait, and an outflow of dense PGW at depth.

Finally, the inflow transport, that brings relatively fresh IOSW to the Gulf, is maximum in spring-summer. This seems to induce an overall decrease in salinity of the Gulf (figure 2b). Indeed, the latter cannot be directly explained by seasonal fluctuations in river discharge nor precipitations. Seasonal modulations of the transports, in turn, reflect deep pressure gradients at Hormuz (see section 4) which fluctuations are induced by dense water formation in the Gulf.

\section{Interannual variability in the Gulf}

We now consider the simulation INTER to characterize the interannual fluctuations in thermohaline structures, circulation and exchanges at Hormuz. Simulation INTER starts from CLIM and is forced by interannual atmospheric conditions from March 1994 to July 2001.

\subsection{Interannual variations of temperature and salinity over the Gulf}

Interannual fluctuations of net and total heat fluxes over the Gulf are dominated by fluctuations in the latent heat fluxes (figure 13 in appendix). The short-wave and sensible heat fluxes show twice as small changes from year to year.

Gulf averaged temperature shows moderate interannual variability (about $1^{\circ} \mathrm{C}$ ) compared to the seasonal cycle (figure 2a, black line). Still, 1997 can be considered as a rather cold year, while 1998 and 1999 were warmer than average. AVHRR satellite (infra-red) images indicate that the warmest summer occurred in 1998 and the coldest winter in 1997 (see also [29]). The model also 
reproduces shorter-period anomalies (not shown), like the anomalous cooling from August to September 2000 (by $3^{\circ} \mathrm{C}$ in the Gulf). Nevertheless, the model tends to overestimate temperature in particular in summer: interannual summer SST ranges from 31 to $35^{\circ} \mathrm{C}$, in this model, from 1994 to 2001 (blue line), while it ranges approximately from 32 to $33^{\circ} \mathrm{C}$ in satellite observations from 2003 to 2005 ([36], their figure 4a). This difference, which may not be entirely attributed to interannual variability, can be attributed to a lack of evaporation in the model in summer which induces a too weak latent heat loss by the ocean.

The seasonal and interannual fluctuations in Gulf averaged temperature directly follow those in total heat flux (figure 6a). Actually, the temperature extrema coincide with the changes of sign of the total heat flux. Since the Gulf is shallow, the heat exchanges are essentially vertical, and furthermore, the heat exchanges at Hormuz are weak compared with the atmospheric forcing. Therefore the relation

$$
\Delta T=\int_{t_{0}}^{t} Q_{\text {Total }} /\left(\rho C_{p} H\right) d t
$$

where $\Delta T$ is the volume averaged change in temperature from time $t_{0}$ to time $t, \rho$ is the density, $C_{p}$ is the heat capacity and $H$ the total depth, is accurate within $0.3^{\circ} \mathrm{C}$ when compared with the modeled interannual temperature change.

Contrary to temperature, interannual variability in Gulf averaged salinity is substantial and actually dominates seasonal variability (figure 2b, black line). Indeed, though the salinity maxima occur between October and March for all years studied, and the minima occur between July and September, the maximal amplitudes range between 39.5 and 40.5 psu and the minima between 39.3 and $40.0 \mathrm{psu}$. This range of seasonal cycle is consistent with that obtained in CLIM (from 39.9 to $40.1 \mathrm{psu}$ ). The seasonality of sea surface salinity is more pronounced (blue line), and the mean seasonal cycle from 1994 to 2001 ranges from 38.6 to $39.4 \mathrm{psu}$, which corresponds well to the observed climatology ([36], their figure 4b). Finally, the total salt content in the Gulf strongly decreases between 1996 and 1999 and increases again in 2000. These variations cannot be directly related to atmospheric fluxes, because of the importance of the exchanges at Hormuz for the salt budget within the Gulf.

In simulation INTER, inflow and outflow transports at the Strait of Hormuz have the same mean value as in CLIM, but much larger variability (figure $2, \mathrm{c}$ and d, black lines). The standard deviation in both transports, equal to $0.046 \mathrm{~Sv}$ for the inflow and $0.043 \mathrm{~Sv}$ for the outflow (both calculated from monthly averages) corresponds well to observations ( $0.04 \mathrm{~Sv}$ for the inflow, [17]), while variability in CLIM (0.025 and $0.022 \mathrm{~Sv}$ respectively) is clearly underestimated. The increase in variability in INTER inflow and outflow transports is mostly affecting variability at the seasonal time scale, suggesting that it is necessary to force the model with interannual atmospheric conditions in order to reproduce the correct magnitude in seasonal variations at the strait. 

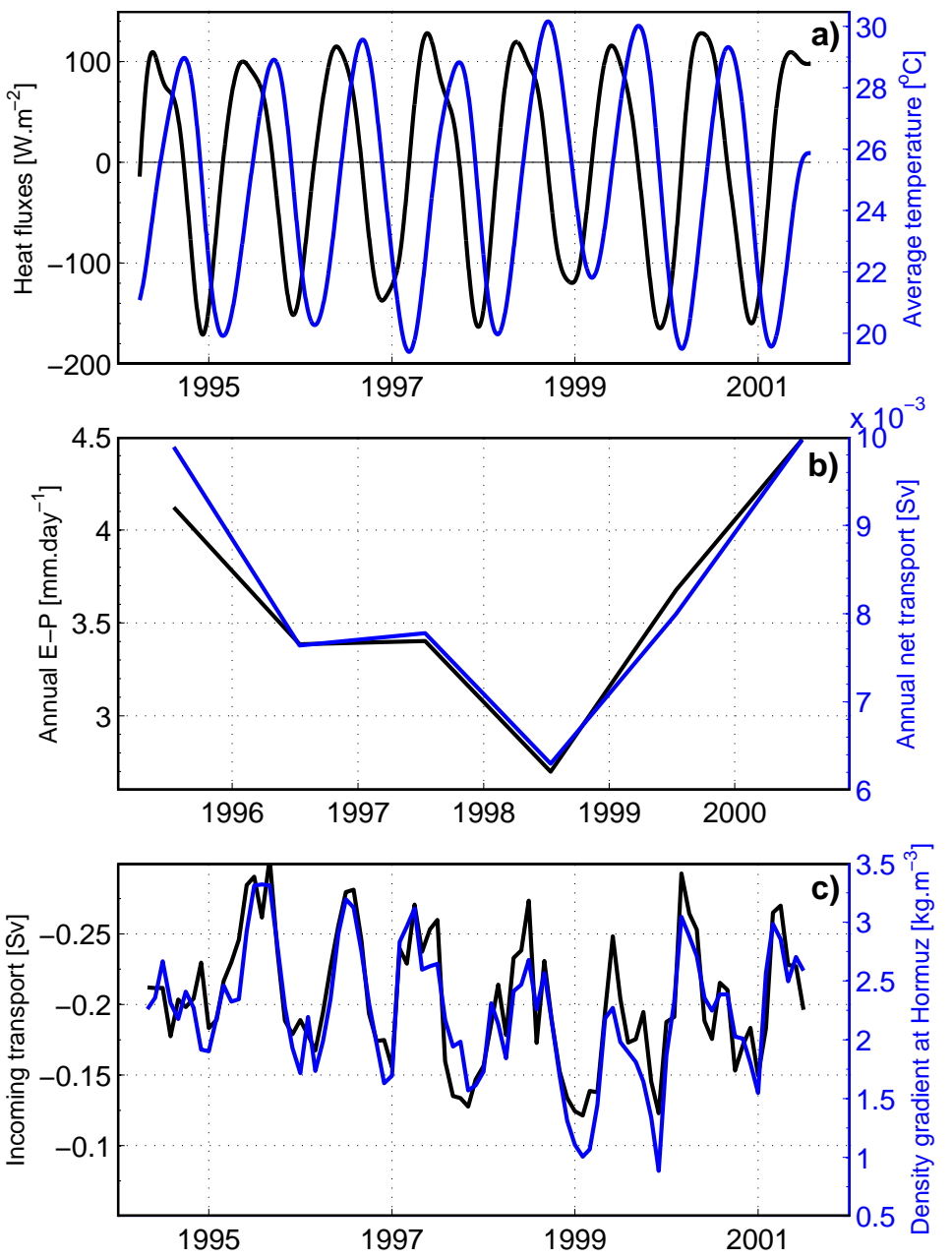

Fig. 6 (a) Surface heat fluxes $\left(Q_{\text {Total }}\right.$, positive from air to sea, black line) and averaged temperature over the Gulf (blue line). (b) Annual mean E-P above the Gulf (black line) and annual mean net transport across the Strait of Hormuz (blue line). (c) inflow transport at the Strait of Hormuz (black line) and difference in density at $75 \mathrm{~m}$ depth between PGW and IOSW (blue line).

Interestingly, the latter does not reflect on the net transport across the strait, which seasonal variability is comparable in CLIM and INTER.

The inflow and outflow transports in INTER also show substantial variability at the interannual timescale. They globally decrease from 1995 to 1999 but these yearly values remain close to those of CLIM (table 4.1). The decrease in exchanges at the strait is a direct consequence from the decrease in salinity over the Gulf (which induces a decrease in density, see below). The net transport is always oriented towards the Gulf. It decreases from 1995 until 
1998 when it reaches its minimum, then increases again in 1999. Thus the net transport is more closely related to the $\mathrm{E}-\mathrm{P}$ flux than are the inflow or outflow separately. Indeed, interannual fluctuations in the net transport exactly coincide with changes in $\mathrm{E}-\mathrm{P}$ (figure $6 \mathrm{~b}$ ). This correlation is clearly understood in terms of the conservation of water mass within the Gulf. It is more difficult to relate the variations in transport directly to the average salinity due to the complexity of the circulation and mixing in the Gulf.

Finally, we computed the density gradient at Hormuz in between two points at $75 \mathrm{~m}$ depth, one within PGW in the Gulf to the west of the strait, the other east of the strait in the Gulf of Oman (out of the PGW core, figure 6c, blue line). The time series exhibit a seasonal cycle peaking in June (February-May for [19] and July-August for [40]) with an average amplitude of $2.23 \mathrm{~kg} / \mathrm{m}^{3}$ comparable with [19] $\left(2.4 \mathrm{~kg} / \mathrm{m}^{3}\right)$. Interannual fluctuations (ranging from 1.6 in 1999 to 2.6 in 1995) are highly correlated (0.89) to the inflow transport (black line).

\begin{tabular}{|l||c|c|c||c||c|}
\hline Year & $\begin{array}{c}\text { Inflow } \\
\mathrm{Sv}\end{array}$ & $\begin{array}{c}\text { Outflow } \\
\mathrm{Sv}\end{array}$ & $\begin{array}{c}\text { Net transport } \\
\mathrm{m}^{3} \mathrm{~s}^{-1}\end{array}$ & $\begin{array}{c}\text { Averaged salinity } \\
\mathrm{m} / \text { year }\end{array}$ \\
\hline 1995 & -0.235 & 0.225 & -9889 & 40.25 & 1.49 \\
\hline 1996 & -0.216 & 0.208 & -7205 & 39.75 & 1.24 \\
\hline 1997 & -0.193 & 0.185 & -8136 & 39.71 & 1.27 \\
\hline 1998 & -0.194 & 0.188 & -6300 & 39.49 & 0.96 \\
\hline 1999 & -0.169 & 0.161 & -7996 & 39.48 & 1.35 \\
\hline 2000 & -0.209 & 0.198 & -11123 & 39.83 & 1.64 \\
\hline
\end{tabular}

Table 1 Yearly averages of the inflow, outflow, and net transport at Hormuz (negative values mean that the flux is oriented towards the Gulf), averaged salinity over the Gulf, and Evaporation minus Precipitation rate over the Gulf.

\subsection{Interannual variations of the thermohaline circulation}

Interannual variations in the transport at Hormuz induce variations in the thermohaline circulation within the Gulf, which are superimposed on the variations of the circulation due to wind. For instance, in May 1996 the surface circulation in the southeastern part of the Gulf has two westward branches which are fed by a strong inflow of IOSW (figure 7a); in May 1999, on the contrary, a single branch of westward surface current is present, along the Iranian coast, driven by a weaker inflow of IOSW at Hormuz (figure 7c). This branch recirculates cyclonically in the southern Gulf. This recirculation is a feature driven by the wind stress. In turn, this recirculation prevents the generation of a second branch of westward surface currents and weakens the inflow at Hormuz. This is a retro-action of the circulation on the exchanges at the strait. Furthermore, salinities in the southwestern part of the Gulf at this season are much higher in 1996 than in 1999, indicating that the evaporation is more intense in 1996, thus creating a larger density gradient between the two 

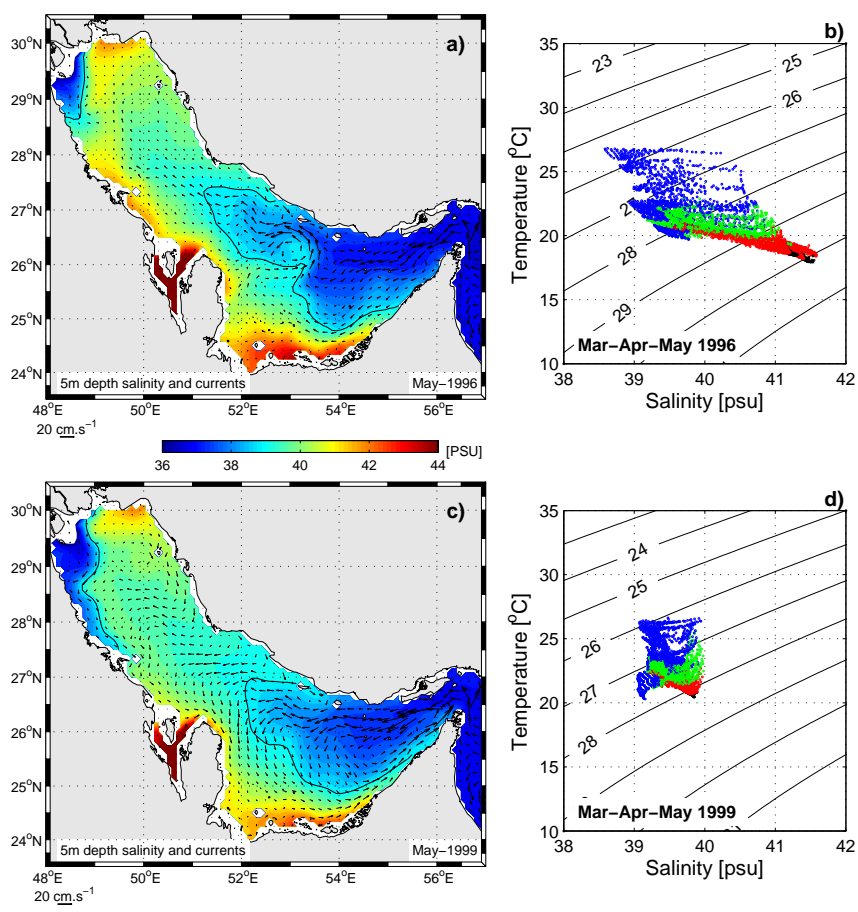

Fig. 7 Maps of (monthly averaged) surface salinity and currents in the Gulf in May 1996 (a) and in May 1999 (c); isohaline 39 psu is located by the black line. Temperature-Salinity diagram in spring in the central region of the Gulf in 1996 (b) and in 1999 (d).

Gulfs and a more intense thermohaline circulation. Therefore, the interannual variations of the circulation result from the variations in evaporation - precipitation which affects the net transport at Hormuz, from the various mechanisms driving the circulation in the Gulf (density currents and wind driven currents), and from their nonlinear interactions. These interannual variations of the E-P budget also influence the vertical structure in salinity of the Gulf. For instance, along the deepest axis of the Gulf, the vertical gradients of salinity are stronger in 1996 than in 1999 (from 38.5 to 41.5 psu and from 39 to 40 psu resp., see figure 7 , b and d), though the two years have similar E-P budgets. In fact, this is a delayed effect of the E-P budgets of the previous years (1995 and 1998) which are very different (much salty water is formed in 1995, which still lies at the bottom of the Gulf in early 1996, contrary to 1998 and 1999). Note that for this season, both in 1996 and 1999, water mass properties in INTER compare better to observations from [3] than those of CLIM (see figures 7b, $7 \mathrm{~d}$ and 5b) which highlights the strong interannual variability. 
4.3 Interannual variability of the characteristics of IOSW and PGW at Hormuz

The inflow of IOSW presents a noticeable seasonal and interannual variability (figure $8 \mathrm{~g}$, plain black line). The monthly averaged salinity ranges between 36.5 and $37.5 \mathrm{psu}$. The current velocity reaches a maximum in spring to early summer generally, but other maxima occur also in February (in 2000) and August (in 1998, figure 8h, plain black line).

Although PGW outflow is negatively correlated with the IOSW inflow, there are notable discrepancies in between the two time series (figure 8h, plain blue line). In general, PGW outflow is maximum in late spring and summer, but other maxima also occur in February-June (1999, 2000). Standard deviation of PGW outflow from monthly time series is $4.57 \mathrm{~cm} / \mathrm{s}$, with $48 \%$ due to seasonality and $15 \%$ due to interannual variability. Those two ratios are respectively smaller than those obtained for the inflow of IOSW (monthly standard deviation being $54 \%$ seasonal and $23 \%$ interannual), which suggests that PGW outflow is more influenced by intraseasonal variability than IOSW outflow. This is consistent with observations and simulations of pulses of PGW outflow at intraseasonal timescale [40] and it may reflect the sporadic discharge of dense waters from the southern banks.

PGW salinity varies between 38.5 and $40.5 \mathrm{psu}$ (figure $8 \mathrm{~g}$, plain blue line). Interannual fluctuations in PGW salinities directly follow interannual fluctuations in the Gulf averaged salinity (cf table 4.1), year 1995 being the saltiest of all (with salinity of PGW outflow larger than $39.75 \mathrm{psu}$ on annual average) and year 1998 being the freshest of all (with salinity PGW outflow smaller than 39.25 psu on annual average). Although PGW salinity mostly varies on the seasonal timescale ( $57 \%$ of the monthly standard deviation is due to the seasonal cycle), it also notably varies on the interannual timescale (25\% of the monthly standard deviation) and more so than the salinity of IOSW (which monthly standard deviation is due for $56 \%$ to seasonality, and for $9 \%$ to interannual variability). This highlights the importance of interannual variability of the salinity of PGW outflow, presumably due to the mechanisms of variability intrinsic to the Persian Gulf (Evaporation minus Precipitations combined with river outflows and wind-driven mixing).

\section{Intraseasonal variability}

The intraseasonal changes in atmospheric conditions are reflected in the surface salinity, temperature and current fields (figure 9). Around July 12, 2001, the strong northwesterly wind generates intense southwestward currents opposing the inflow of IOSW, which detaches from the Iranian coast and recirculates cyclonically (top panels). Around July 26, 2001, a moderate east-northeasterly wind favors the progression of IOSW along the Iranian coast and a regional anticyclonic circulation in the north-western part of the Gulf (bottom panels). The former case, with strong northwesterly winds strengthening the cyclonic 

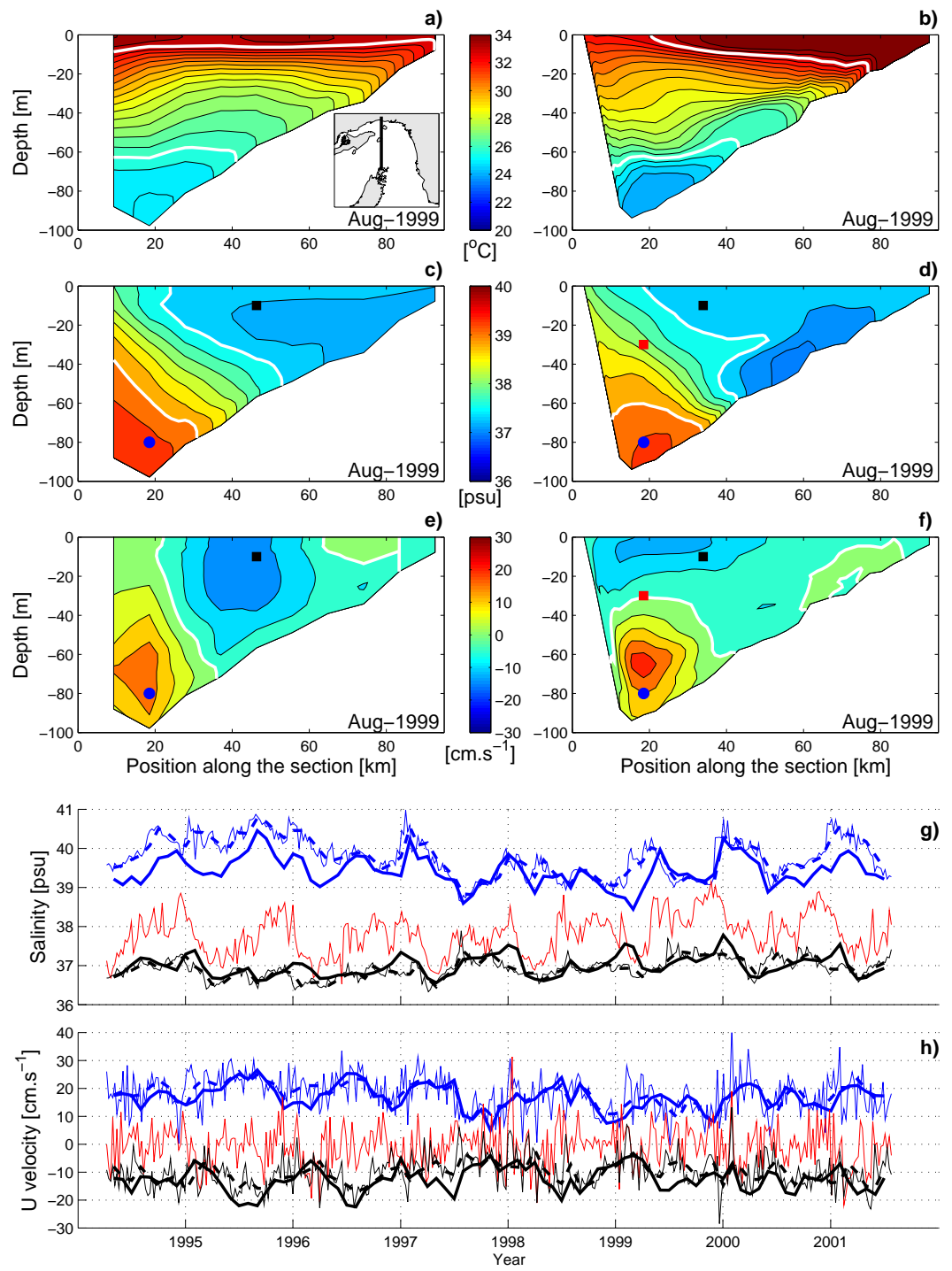

Fig. 8 Cross-sections of temperature (a, b), salinity (c, d) and normal velocity (e, f) at Hormuz for INTER (left panels, a, c, e) and INTER-HR (right panels, b, d and f) averaged over the month of August 1999; time series of salinity (g) and normal velocity (h) in the IOSW inflow (blue lines), in the deep PGW outflow (black lines) and at $35 \mathrm{~m}$ depth, above the deep outflow (red line, only for INTER-HR), monthly averaged for INTER (thick lines) and INTER-HR (dashed lines). The location of the section is shown on the subset of panel a, while the points where time series are extracted are shown by a black square (inflow), a blue circle (deep outflow) and a red square (35 $\mathrm{m}$ depth, above the deep outflow) in panels c-f. In the cross-sections, white lines locate 26 and $33^{\circ} \mathrm{C}$ isotherms, 37.5 and 39 isohalines and $0 \mathrm{~cm} / \mathrm{s}$ isotach. For INTER-HR, the time series are also shown at higher frequency (7-day outputs filtered by Demerliac, thin lines). 

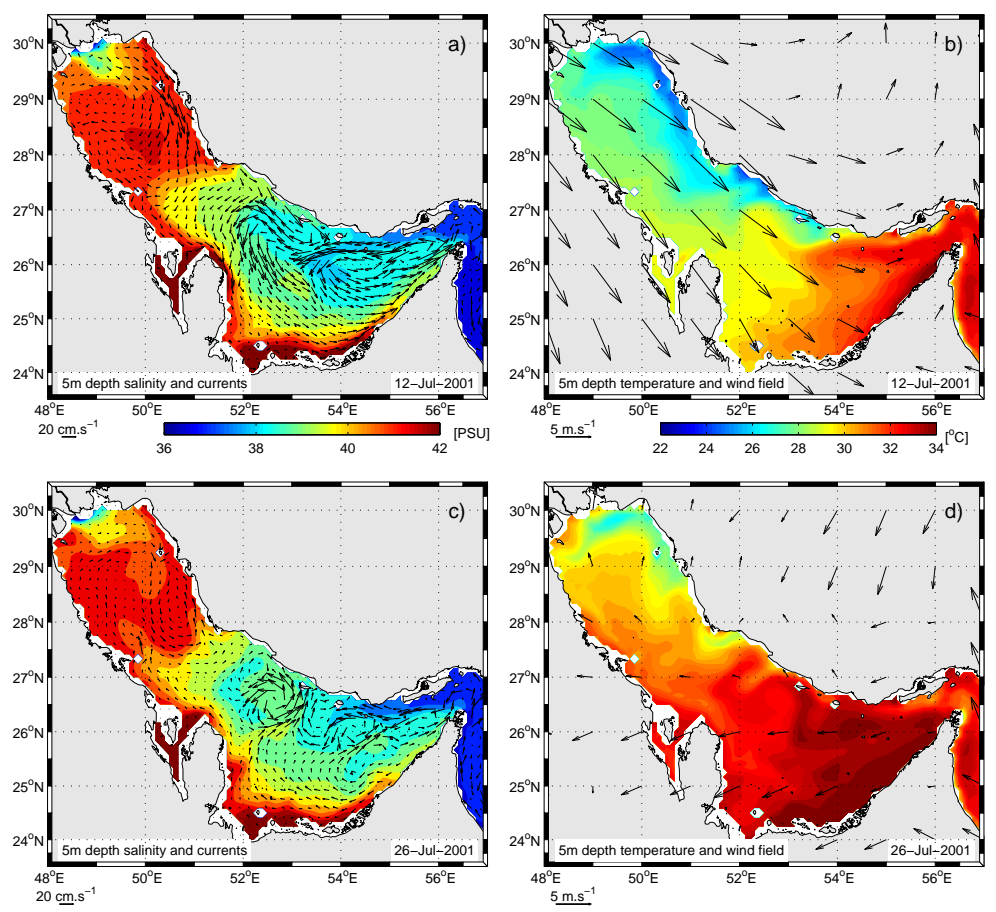

Fig. 9 Surface salinity (a and c, color shading), surface currents (filtered from tide, a and $\mathrm{c}$, arrows), wind field ( $\mathrm{b}$ and $\mathrm{d}$, arrows) and surface temperature (b and d, color shading) for a situation of intense northwesterly wind (averaged over 71 hours) on July 12, 2001 (top panels, a and b) and a situation of weak northeasterly wind on July 26, 2001 (bottom panels, c and d).

recirculation of IOSW, has also been described in [37]. We note that this situation tends to advect more freshwater towards the southern part of the Gulf (figure 9a, color shading). Mesoscale eddies (ICE) are also slightly modified by the wind changes. Both cyclonic eddies (centered at 52.5 and $54.2^{\circ} \mathrm{E}$ around July 12) become weaker around July 26 whereas an anticyclonic eddy appears in between the cyclonic eddies. This result is consistent with [37] sensitivity study to wind stress (their figure 9). INTER simulation also reproduces winddriven short-term flow reversal along the Arabian coast as revealed by drifter trajectories and other model simulations ([37]). Indeed, between 52 and $55^{\circ} \mathrm{E}$, the model currents along the southern coast are oriented toward the east on July 12 and toward the west on July 26, consistent with the changes in wind direction.

Regarding the structure of the Shatt-al-Arab plume, we note that using 6hourly wind forcing improves the realism of the structure, as our model results compare better with observations than e.g. the work by [8] or [19] that used low-frequency winds. 
Along the northern Iranian coast (north of $27^{\circ} \mathrm{N}$ ), northwesterly wind conditions drive a coastal upwelling that brings colder water along the coast (figure $9 \mathrm{~b}$, color shading), as suggested by observations ([33]). This upwelling disappears during east-northeasterly wind conditions (figure $9 \mathrm{~d}$, color shading).

\section{Impact of horizontal resolution}

We describe here the results of INTER-HR in comparison with those of INTER.

6.1 Salinity, temperature and circulation in the Gulf

The most striking impact of increasing the resolution is the decrease of Gulf averaged salinity by about 0.30 after 2 years (figure $2 \mathrm{~b}$, red line). After this adjustment, the difference in salinity between INTER and INTER-HR is constant in time and fluctuations in salinity at monthly to interannual timescales are very similar in the two simulations. When considering maps of surface salinity rather than the averaged salinity over the Gulf, we note that salinity in the southeastern and northwestern parts of the Gulf decrease by about 1 psu (this is visible in the monthly average of August 1999, figure 10). On the contrary, the average temperature in the Gulf in INTER-HR does not change noticeably from INTER (figure $2 \mathrm{a}$, red line). Indeed, temperature depends on the atmospheric forcings that are the same for INTER and INTER-HR simulations (total heat fluxes average to 1.2 and $5.8 \mathrm{~W} / \mathrm{m}^{2}$, which is not significantly different considering the standard deviation of both time series, see appendix) while salinity in the Gulf is influenced by transport at Hormuz and therefore depends on circulation.

As illustrated in August 1999, the circulation in INTER-HR is somehow different from that in INTER (figure 10): the IOSW inflow along the Iranian coast penetrates farther to the Northwest, which is more realistic and the plume from the Shatt-al-Arab is better represented along the Arabian coast. In addition, there are more mesoscale structures in INTER-HR (figure 11) than in INTER (figure 4), as expected from the increase in horizontal resolution, and the mesoscale features in INTER-HR are in better agreement with those described in [37], although they remain less stationary than in [37] as discussed for CLIM. Also there are more contrasts in between the water mass characteristics in and out of the mesoscale features, suggesting that horizontal gradients are larger in INTER-HR than in INTER. Finally, in August 2000, ICC is more coherent and continuous from the Strait of Hormuz to the northern part of the basin, suggesting that it is better resolved by INTER-HR than by INTER. 


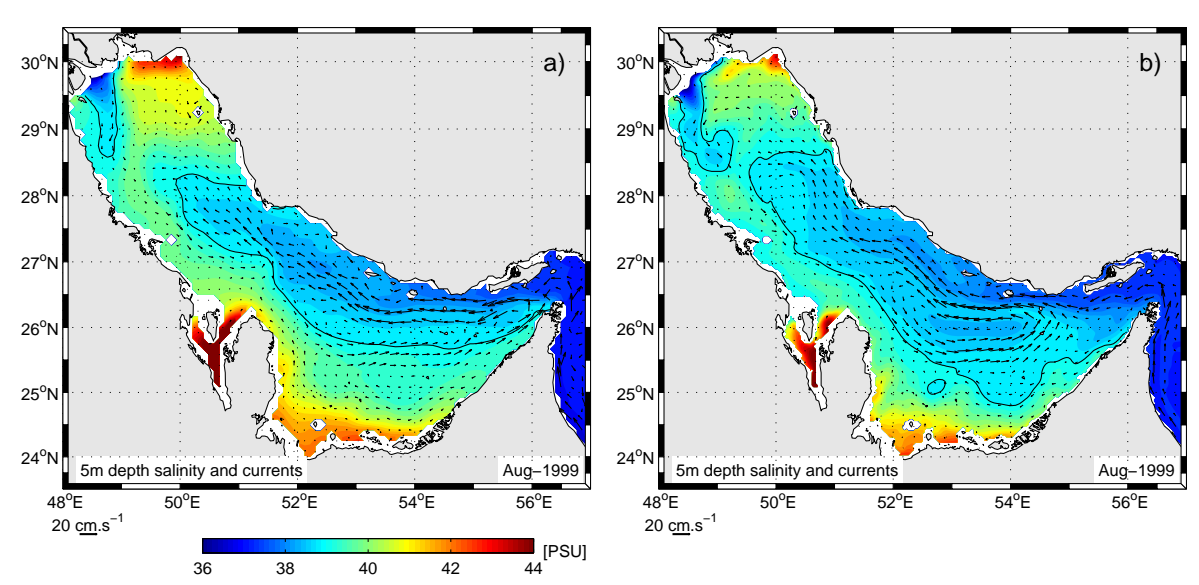

Fig. 10 Surface salinity and currents (only one arrow every $20 \mathrm{~km}$ is shown) for August 1999 (monthly average) in INTER (a) and INTER-HR (b). Isohaline 39 psu is located by the black line.

\subsection{Circulation and thermohaline structure at Hormuz}

The net transport at Hormuz in INTER-HR is exactly the same as in INTER, except for one month in 2000 presumably due to a numerical error that occurred while running the model (figure 2e, red line). This presumably reflects the fact that the fluxes of Evaporation minus Precipitation are very close in INTER and INTER-HR (see appendix, the mean E-P rates are not significantly different). Still, inflow and outflow transports at Hormuz are $0.04 \mathrm{~Sv}$ smaller in INTER-HR compared to INTER, but highly correlated to those in INTER at intraseasonal to interannual timescale (figure 2, c and d, red line).

Indeed, increasing the resolution influences the thermohaline structure and circulation at Hormuz (figure 8, a-f). Overall, the gradients in temperature and salinity, in the horizontal and vertical direction, are more intense in INTER-HR than in INTER, suggesting that there is less spurious horizontal and vertical mixing in between IOSW and PGW in the higher-resolution simulation. Hence salinity of the deep outflow is higher in INTER-HR than in INTER. Nevertheless, variability in the salinity of the outflow is comparable in INTER-HR and INTER, suggesting that the processes of variability in dense water formation are not affected by model resolution. On the other hand, there is less variability in the salinity of the inflow vein in INTER-HR compared to INTER (figure $8 \mathrm{~g}$, black lines), presumably due to the reduced mixing within the strait at higher resolution.

The intensity of the currents in the core of the inflow and outflow veins through the strait, is very similar in the two simulations (figure 8h). Monthly averages of the currents reach $15 \mathrm{~cm} / \mathrm{s}$ (in the inflow) to $25 \mathrm{~cm} / \mathrm{s}$ (in the outflow) but higher frequency model outputs reveal currents up to $40 \mathrm{~cm} / \mathrm{s}$ (in the outflow) and $30 \mathrm{~cm} / \mathrm{s}$ (in the inflow), close to maximal observations (in [36] $30-50 \mathrm{~cm} / \mathrm{s}$ for outflow and $30 \mathrm{~cm} / \mathrm{s}$ for inflow). Nevertheless, the structure 

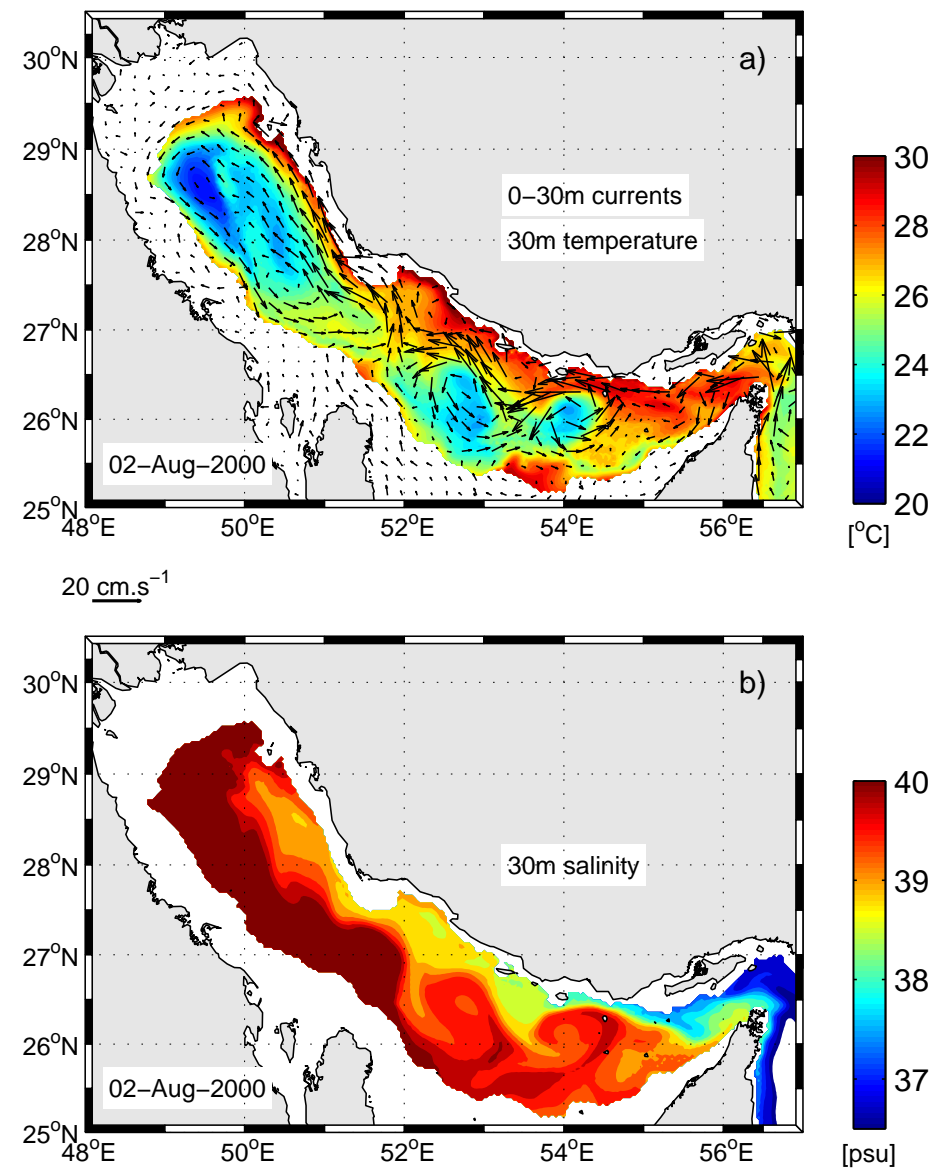

Fig. 11 Snapshot of temperature and velocity (only one arrow every $20 \mathrm{~km}$ is shown) in (a) and salinity (b) in August 2000 in INTER-HR. Currents are averaged over the upper $30 \mathrm{~m}$, while temperature and salinity are extracted at $30 \mathrm{~m}$ depth.

of the current changes from barotropic in INTER to baroclinic in INTER$\mathrm{HR}$ (figure 8, e and $\mathrm{f}$ ). Also the core of the outflow vein is better resolved, $20 \mathrm{~m}$ above sea floor, with higher-resolution. Finally, there is high frequency variability in salinity at $35 \mathrm{~m}$ depth, above the main deep outflow vein, with fluctuations of more than 1 that last for 1 to 3 weeks roughly (figures 8, g and h, red lines), as noted by [36] in observations and in a higher resolution model outputs $(1 \mathrm{~km})$. The rapid increase of salinity at this depth corresponds to reverses of the flow, i.e. extensions of the deep vein in the upper ocean.

Lastly, we compare the time series of vertical profiles of temperature and salinity in INTER-HR with the mooring observations of [17] (figure 12, to be compared with their figure 7). Simulated temperature ranges from 19 to $33^{\circ} \mathrm{C}$, while observations range from 20 to $33^{\circ} \mathrm{C}$. Modifications of the temperature 

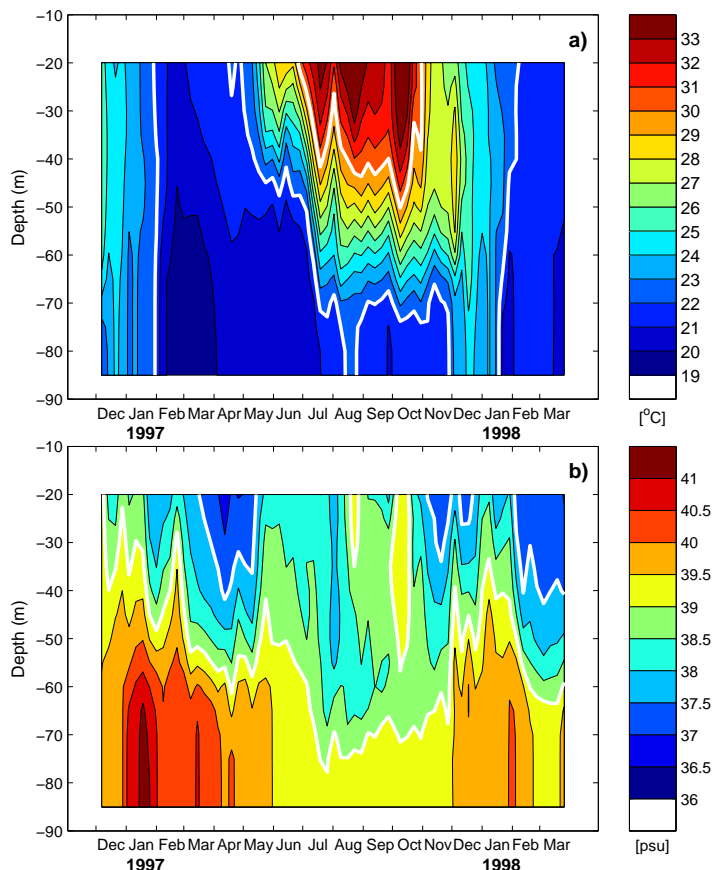

Fig. 12 Time series of the temperature (a) and salinity (b) profiles from December 1997 to March 1998 in the strait close to [17] mooring site (whose position is located by the red square in figure 1). White lines indicate 22 and $30^{\circ} \mathrm{C}$ isotherms and 37.5 and $39 \mathrm{psu}$ isohalines.

profile occur simultaneously in the model and in observations: deepening of the mixed layer in November, cooling from December to February, restratification in May and warming from June to October. Mixed layer depth at about 50m in the model also compares well with observations. With regard to salinity, there is a surface inflow of low salinity in March-April 1997 and other spikes of low salinity from November 1997 to March 1998 (with salinities as low as $37.5 \mathrm{psu}$ down to $40 \mathrm{~m}$ depth), as observed. At depth, there are pulses of high salinity (up to $41 \mathrm{psu}$ ) in January and March 1997, then in December and February 1998, again as found in observations. The major difference between model and observed profiles is the underestimate of salinity at depth, of the order of $0.5 \mathrm{psu}$, from June to December 1997 suggesting that the salinity of the flow coming from northwestern part of the gulf is too low. Hence this model compares better with those observations than models of previous studies, e.g. [40] whose climatological run is too warm and too salty and [36] whose model underestimates mixed layer depth and salinity (by roughly $1 \mathrm{psu}$, though this model reproduces a different year than that of observations). 


\section{Summary and conclusions}

This study presents the development, validation and analysis of a realistic model of the Persian Gulf. Reference experiment has a resolution of $9 \mathrm{~km}$ but we also present the results of a higher resolution configuration $(3 \mathrm{~km})$. CLIM experiment is first run with climatological forcings, which is used to validate the model and describe the seasonal circulation and thermohaline structure within the Gulf, then interannual atmospheric conditions are applied to describe intraseasonal to interannual variability. Sensitivity experiments to model settings (atmospheric forcing datasets, heat and freshwater fluxes, vertical mixing and horizontal resolution) have been performed in order to have the best comparison with all available observations.

The circulation and thermohaline structures in the Gulf are well reproduced by the model, both for the mean state and for the seasonal variability. A barotropic cyclonic gyre dominates the general circulation from April to July. In late summer, this structure breaks down into smaller mesoscale eddies, and this continues further in winter as wind intensifies and stratification decreases due to winter cooling. Dense salty water is formed in winter in the northwest part of the Gulf and in the southern banks. A permanent southeastward deep current advects dense water from the northwest towards the Strait of Hormuz all year long, while dense water formed in the southern banks only reach Hormuz from November to April. Water masses of the upper ocean are also well reproduced by the model, except that the model is slightly too warm in summer. A seasonal decrease in salinity in the Gulf is related with the increased inflow of IOSW through the Strait of Hormuz. The outflow transport through the strait reflects the dense water accumulation at the bottom of the Gulf near the strait. This increases the deep pressure gradient across the strait thus the outflow, hence the inflow by continuity. Notwithstanding, no specific correlation is observed locally in the strait between deep salinity and deep currents.

We then describe variability on the interannual timescale in the thermohaline structures and circulation in the Gulf. Temperature fluctuations, which correspond well with observations, are directly related to changes in the surface heat fluxes. Interannual variability in Gulf averaged salinity is substantial and actually dominates seasonal variability. These variations cannot be directly related to atmospheric fluxes, because of the importance of the exchanges at Hormuz for the salt budget within the Gulf. Interannual fluctuations in PGW salinities directly follow interannual fluctuations in the Gulf averaged salinity and explain $25 \%$ of the total variance, while interannual fluctuations in the incoming IOSW salinity only explain $9 \%$ of the total variance.

The interannual variations of the circulation result from the variations in evaporation - precipitation which affect the net transport at Hormuz, from the various mechanisms driving the circulation in the Gulf (density currents and wind driven currents), and from their nonlinear interactions. These interannual variations of the E-P budget also influence the vertical structure in salinity of the Gulf. We note that interannual fluctuations of the inflow 
(and outflow) transport are highly correlated to the density gradient through Hormuz. Finally, inflow and outflow transports at the Strait of Hormuz in simulation INTER have the same mean value than in CLIM, but much larger variability mostly occurring at the seasonal time scale, which corresponds better to observations. This suggests that it is necessary to force the model with atmospheric conditions including interannual variations in order to reproduce the correct magnitude in seasonal variations at the strait.

Noticeable changes at intraseasonal frequency also occur in the thermohaline properties and the currents, induced by the high-frequency tidal and atmospheric forcings. They affect the shape and intensity of the cyclonic circulation, the position of the river plume, the development of an upwelling along the northwestern Iranian coast, the coastal reversal flows along the Arabian coast and mesoscale eddy distribution.

All the results described above still hold in the higher-resolution simulation (with $3 \mathrm{~km}$ resolution). Nevertheless, the latter seems to improve the realism of the solution compared to the companion lower resolution simulation. Indeed, the ICC is better represented, as well as mesoscale eddies that bring the freshwater to the interior of the basin. Hence, the high-resolution simulation is slightly fresher than the lower-resolution one. The structure of the currents and water masses near the Strait of Hormuz remain close to observations. Overall, vertical and horizontal tracer gradients are better resolved at high resolution and the structure of the flow is more baroclinic than at lower resolution. But observations are lacking to validate further the high resolution simulation on an interannual perspective. Although the high-resolution model does not bring new results compared to the lower resolution model, we still recommend that future models of the Gulf have at least $3 \mathrm{~km}$ resolution so as to reproduce the influence of mesoscale eddies on the main circulation. These mesoscale processes, generated locally by high-frequency wind fluctuations, significantly modify the exchanges at the Strait of Hormuz, hence the contribution of the Persian Gulf to the global circulation of heat and salt.

Finally, all three simulations overestimate temperature in summer, when salinity at the strait is slightly underestimated in INTER-HR. This suggests that the evaporation rate may be underestimated, which could be fixed by an ad hoc correction. Ideally, such a correction should be modulated temporally and spatially, but this cannot be done without more accurate and numerous estimates of the evaporative fluxes. Similarly, uncertainties remain in temporal variations in river discharges, for which observations are lacking. Hence we insist on the need for more observations of the evaporation rate and river discharges to the Persian Gulf to constrain the models better and reduce their biases in water mass characteristics.

Acknowledgements The authors thank SHOM, IFREMER, Universite de Bretagne Occidentale, Universite P et M Curie, and Museum National d'Histoire Naturelle for their support during the course of this work. This work was achieved in partial fulfillment of the requirements for S.P.'s PhD degree in physical oceanography, defended December 7, 2005, at 
the University of Brest. We acknowledge suggestions of all three reviewers that contributed to improving the paper substantially.

\section{Appendix}

All simulations (CLIM, INTER and INTER-HR) use the method of flux correction devised by Barnier ([4]). This method modifies the heat fluxes with a relaxation of the model towards the observed sea surface temperature. The total heat flux $Q_{\text {Total }}$ is the sum of the net heat flux $Q_{\text {Net }}$ (itself the sum of all atmospheric heat fluxes) and of the correction indicated above:

$$
Q_{\text {Total }}=Q_{\text {Net }}\left(S S T^{c l i m}\right)-\frac{\partial Q_{\text {Net }}}{\partial S S T^{c l i m}}\left(S S T^{\text {clim }}-S S T^{\text {mod }}\right)
$$

where $S S T^{\text {clim }}$ is the sea surface temperature from GDEM and $S S T^{\text {mod }}$ is the sea surface temperature from the model. GDEM sea surface temperature was chosen for compatibility with the open boundary conditions. If positive, $Q_{\text {Total }}$ represents a gain of heat for the ocean. The mean fluxes for all fluxes in all three simulations is indicated in table 2. The values for $Q_{\text {Total }}$ lie in the ranges commonly agreed upon in the literature: observations range from $-7 \pm 4 \mathrm{~W} / \mathrm{m}^{2}$ ([17]) to $+4 \mathrm{~W} / \mathrm{m}^{2}([17])$, while simulated values are $-3 \mathrm{~W} / \mathrm{m}^{2}$ ([37]), $-4 \mathrm{~W} / \mathrm{m}^{2}([19])$ and -7 to $-10.3 \mathrm{~W} / \mathrm{m}^{2}([39])$. Evaporation rate in all three simulations are also comparable with observations. Note that the model of [19] has an evaporation rate of $1.8 \mathrm{~m}$ /year that is larger than observations and the present simulations. Estimates of precipitation rate from observational climatologies are about $0.15 \mathrm{~m} /$ year ([17]), which is smaller than used in all three simulations. However, the rate of Evaporation minus Precipitation in the three simulations is comparable with that in the modeling study of [39] (from 1.2 to $1.43 \mathrm{~m} /$ year). Finally, with Runoff fluxes equivalent to $0.18 \mathrm{~m} /$ year in all three simulations, the overall $\mathrm{E}-\mathrm{P}-\mathrm{R}$ in the simulations equals 1.18 (CLIM), 1.14 (INTER) and $1.06 \mathrm{~m} /$ year (INTER-HR), which is smaller than the indirect estimated $1.68 \pm 0.39$ from transports ([17]).

The mean heat fluxes are not significantly different in INTER and INTERHR (Student's t-test at 95\% significant level) except for sensible fluxes. For the latter that range roughly from -53 to $95 \mathrm{~W} / \mathrm{m}^{2}$ over the Gulf, the difference in sea/land area (islands and coast lines) may explain the mean difference in in between INTER and INTER-HR.

\section{References}

1. Abdelrahman S.M. and F. Ahmad, A note on the residual currents in the Arabian Gulf. Continental Shelf Research, 15, 1015-1022 (1995).

2. Ahmad R. and S.A.F. Sultan, Annual mean surface heat fluxes in the Arabian Gulf and the net heat transport through the Strait of Hormuz. Atmosphere Ocean, 29, 54-61 (1990).

3. Alessi C. A., H. D. Hunt, and A. S. Bower, Hydrographic data from the U.S. Naval Oceanographic Office: Persian Gulf, Southern Red Sea, and Arabian Sea 19231996, Woods Hole Oceanog. Inst. Tech. Rep., WHOI-99-02 (1999). 


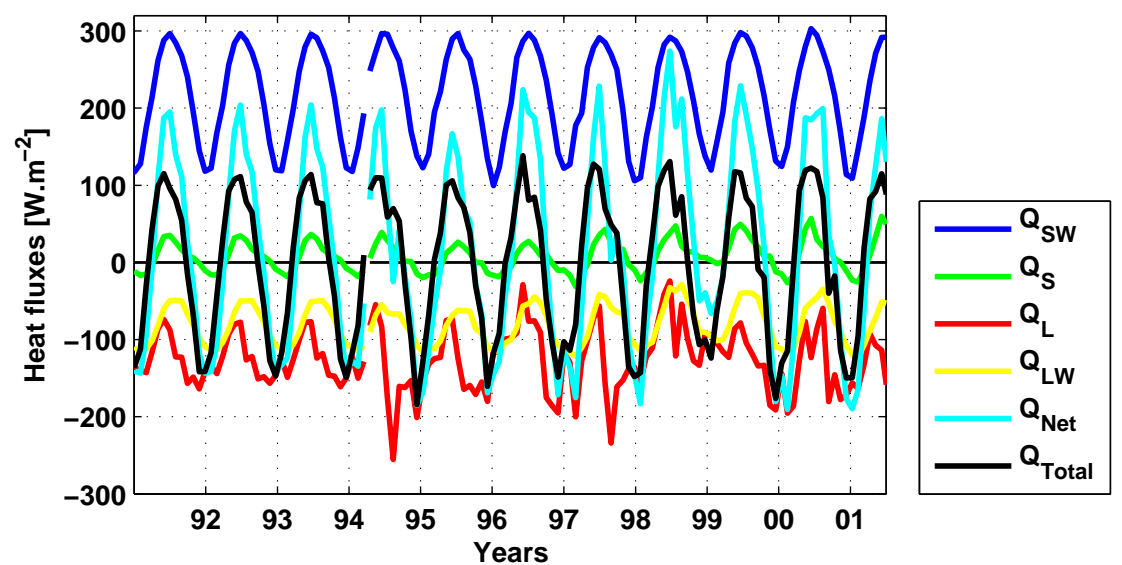

Fig. 13 Interannual time series of the (monthly averaged) heat fluxes in $\mathrm{W} / \mathrm{m}^{2}$ for the Persian Gulf (spatially averaged over the basin): $Q_{\mathrm{SW}}$ is the short-wave heat flux, $Q_{\mathrm{S}}$ the sensible heat flux, $Q_{\mathrm{L}}$ the latent heat flux, $Q_{\mathrm{LW}}$ the long-wave heat flux, $Q_{\mathrm{Net}}$ the net heat flux and $Q_{\text {Total }}$ the total heat flux.

\begin{tabular}{|l||c|c|c||c||}
\hline Fluxes & CLIM & INTER & INTER-HR & COADS-SOC-c \\
\hline Shortwave & 216.2 & 219.0 & 221.1 & 211 \\
\hline Latent & -125.0 & -127.3 & -120.1 & -122 \\
\hline Sensible & 7.5 & 9 & -6.9 & -7 \\
\hline Longwave & -81.8 & -80.0 & -80.0 & -78 \\
\hline Net & 16.9 & 20.5 & 28.5 & 4 \\
\hline Total & $\mathbf{- 3 . 0}$ & $\mathbf{1 . 2}$ & $\mathbf{5 . 8}$ & $\mathbf{4}$ \\
\hline \hline Evap. & $\mathbf{1 . 5 8}$ & $\mathbf{1 . 6 1}$ & $\mathbf{1 . 5 1}$ & $\mathbf{1 . 5 8}$ \\
\hline Prec. & 0.21 & 0.24 & 0.24 & - \\
\hline E-P & 1.36 & 1.32 & 1.24 & - \\
\hline
\end{tabular}

Table 2 Basin-averaged mean heat fluxes $\left(\mathrm{W} / \mathrm{m}^{2}\right)$, Evaporation and Precipitation rate (m/year) in CLIM (1980-1994), INTER (1995-2000) INTER-HR (1995-2000) and the SOC air-sea flux climatology (1980-1997, [18]) corrected by [17].

4. Barnier B., Siefridt L. and P. Marchesiello, Thermal forcing for a global ocean circulation model using a three-year climatology of ECMWF analyses. Journal of Marine Systems, 6 , 363-380 (1995).

5. Bignami F., Marullo S., Santoleri R. and M.E. Schiano, Long-wave radiation budget in the Mediterranean Sea. Journal of Geophysical Research, 100, C2, 2501-2514 (1995).

6. Blain C.A., Modeling three-dimensional thermohaline-driven circulation in the Arabian Gulf. Estuarine and Coastal Modeling. Proceedings of the 6th International Conference. Spaulding M.L. and Butler H.L. eds. 74-93. American Society of Civil Engineers (2000).

7. Brewer P.G., Fleer A.P., Kadar S., Shafer D.K. and C.L. Smith, Chemical oceanography data from the Persian Gulf and the Gulf of Oman. Woods Hole Oceanographic Institution technical Report 78-37, 105 (1978).

8. Chao S.Y., Kao T.W. and K.R. Al Hajri, A numerical investigation of circulation in the Arabian Gulf. Journal of Geophysical Research, 97, C7, 11219-11236 (1992).

9. Defant A., Physical Oceanography, Vol.2, Pergamon Press (1960).

10. Demerliac, A., Le niveau de la mer. Calcul du niveau moyen journalier, Service Hydrographique et Océanographique de la Marine, Ann. Hydrogr., 741, 4957 (1974). 
11. Emery K.O., Sediments and water of the Persian Gulf. Bull. Am. Assoc. Pet. Geol., 40, 2354-2383 (1956).

12. Gaspar P., Gregoris Y. and J.M. Lefevre, A simple eddy kinetic energy model for simulations of the oceanic vertical mixing: test at station Papa and long-term upper ocean study site. Journal of Geophysical Research, 95, 16179-16193 (1990).

13. A. Gill A., Atmosphere-Ocean Dynamics, Academic Press, 30, Internatinal Geophysics Series, W. Donn (1982).

14. Horton C., Clifford M., Schmitz J. and B. Hester, SWAFS: Shallow Water Analysis and Forecast System, overview and status report. NAVOCEANO (1994).

15. Hugues P. and J.R. Hunter, A proposal for a physical oceanography program and numerical modeling in the KAP region. Project for Kuwait Action Plan 2/2. UNESCO. Paris (1980).

16. Hunter J.R., The physical oceanography of the Arabian Gulf: A review and theoretical interpretation of previous measurements. First Gulf Conference on Environment and Pollution, Kuwait (1982).

17. Johns W.E., Tao F., Olson D.B., Josey S.A., Grist J.P. and D.A. Smeed, Observations of seasonal exchange though the Straits of Hormuz and the inferred heat and freshwater budgets of the Persian Gulf. Journal of Geophysical Research, 108, C2, 3391-3409 (2003).

18. Josey, S. A., Kent E. C. , and P. K. Taylor, New insights into the ocean heat budget closure problem from analysis of the SOC air-sea flux climatology, Journal of Climate, 12, 28562880 (1999).

19. Kämpf J. and M. Sadrinasab, The circulation in the Persian Gulf: a numerical study. Ocean Science, 2, 27-41 (2006).

20. Koske P., Hydrographische Verhaltnisse in Persischen Golf aus Grund von beobachtungen von F.S. Meteor in Fruhjahr 1965. Meteor Forsch. Ergebn., 11, 58-73 (1972).

21. Lardner R.W., Belen M.S. and H.M. Cekirge, Finite difference models for tidal flows in the Arabian Gulf. Computation and Mathematics with Applications, 8, 6, 425-444 (1982).

22. Lazure P., and F. Dumas, An externalinternal mode coupling for a 3D hydrodynamical model for applications at regional scale (MARS), Advances in Water Resources, 31, 2, 233-250 (2008).

23. Luyten P., Deleersnijder E., Ozer J. and K.G. Ruddick, Presentation of a family of turbulence closure models for stratified shallow water flows and prelinimary application to the Rhine outflow region. Continental Shelf Research, 16, 1, 101-130 (1996).

24. Matsuyama M., Senjyu T., Ishimaru T., Kitade Y., Koike Y., Kitazawa A., Miyazaki T. and H. Hamada, Density front in the Strait of Hormuz. Journal of Tokyo University of Fisheries, 81, 85-92 (1994).

25. Munk W.H. and E.R. Anderson, Note of the theory of the thermocline. Journal of Marine Research, 7, 276-295 (1948).

26. Nunes Vaz, R. A. and J. H. Simpson, Turbulence closure modeling of estuarine stratification, Journal of Geophysical Research, 99, C8, 16143-16160 (1994).

27. Pacanowski R.C. and S.G.H. Philander, Parameterization of vertical mixing in numerical models of tropical ocean. Journal of Physical Oceanography, 11, 1443-1451 (1981).

28. Pous S., Carton X. and P. Lazure, Hydrology and circulation in the Strait of Hormuz and the Gulf of Oman ; results from the GOGP99 Experiment. Part I. Strait of Hormuz. Journal of Geophysical Research, 109, C12037, doi:10.1029/2003JC002145, 1-15 (2004a).

29. Pous S., Carton X. and P. Lazure, Hydrology and circulation in the Strait of Hormuz and the Gulf of Oman ; resultss from the GOGP99 Experiment. Part II. Gulf of Oman. Journal of Geophysical Research, 109, C12038, doi:10.1029/2003JC002146, 1-26 (2004b).

30. Pous S., Carton X. and P. Lazure, A process study of the tidal circulation in the Persian Gulf. Open J. Mar. Sciences, 2, 4, 131-140 (2012).

31. Pous S., Carton X. and P. Lazure, A process study of the wind-induced circulation in the Persian Gulf. Open J. Mar. Sciences, 3, 1, 1-11 (2013).

32. Proctor R.. Flather R.A. and A.J. Elliott, Modeling tides and surface drift in the Arabian Gulf: application to the Gulf oil spill, Continental Shelf Research, 14, 5, 531-545 (1994).

33. Reynolds R.M., Physical Oceanography of the Gulf, Strait of Hormuz, and the Gulf of Oman - Results from the Mt Mitchell Expedition. Marine Pollution Bulletin, 27, 35-59 (1993).

34. Smagorinsky J., General circulation experiments with the primitive equations - i. the basic experiment, Monthly Weather Review, 91, 99-165 (1963). 
35. Swift S.A. and A.S. Bower, Formation and circulation of dense water in the Persian Gulf. Journal of Geophysical Research, 108, C1, 3004, doi:10.1029/2002JC001360 (2003).

36. Thoppil P.G. and P.J. Hogan, On the mechanisms of episodic salinity outflow events in the Strait of Hormuz. Journal of Physical Oceanography, 39, 1340-1360 (2009).

37. Thoppil P.G. and P.J. Hogan, A modeling study of circulation and eddies in the Persian Gulf. Journal of Physical Oceanography, 40, 2122-2134 (2010).

38. Yao F., Water mass formation and circulation in the Persian Gulf and Water exchange with the Indian Ocean. PhD thesis, University of Miami, 2008-12-18 (available from http://scholarlyrepository.miami.edu) (2008).

39. Yao F. and W.E. Johns, A HYCOM modeling study of the Persian Gulf. 1. Model configurations and surface circulation. Journal of Geophysical Research, 115, C11017, doi:10.1029/2009JC05781 (2010a).

40. Yao F. and W.E. Johns, A HYCOM modeling study of the Persian Gulf. 2. Formation and export of Persian Gulf Water. Journal of Geophysical Research, 115, C11018, doi:10.1029/2009JC05788 (2010b). 